University of Nebraska - Lincoln

DigitalCommons@University of Nebraska - Lincoln

Publications, Agencies and Staff of the U.S.

Department of Commerce

U.S. Department of Commerce

2012

\title{
North American Land Data Assimilation System: A Framework for Merging Model and Satellite Data for Improved Drought Monitoring
}

\author{
Justin Sheffield \\ Princeton University, justin@princeton.edu \\ Youlong Xia \\ National Oceanic and Atmospheric Administration \\ Lifeng Luo \\ Michigan State University \\ Eric F. Wood \\ Princeton University \\ Michael Ek \\ National Oceanic and Atmospheric Administration, ek@ucar.edu
}

See next page for additional authors

Follow this and additional works at: https://digitalcommons.unl.edu/usdeptcommercepub

Sheffield, Justin; Xia, Youlong; Luo, Lifeng; Wood, Eric F.; Ek, Michael; and Mitchell, Kenneth E., "North American Land Data Assimilation System: A Framework for Merging Model and Satellite Data for Improved Drought Monitoring" (2012). Publications, Agencies and Staff of the U.S. Department of Commerce. 555.

https://digitalcommons.unl.edu/usdeptcommercepub/555

This Article is brought to you for free and open access by the U.S. Department of Commerce at DigitalCommons@University of Nebraska - Lincoln. It has been accepted for inclusion in Publications, Agencies and Staff of the U.S. Department of Commerce by an authorized administrator of DigitalCommons@University of Nebraska - Lincoln. 
Authors

Justin Sheffield, Youlong Xia, Lifeng Luo, Eric F. Wood, Michael Ek, and Kenneth E. Mitchell 
Published in Remote Sensing of Drought: Innovative Monitoring Approaches, edited by Brian D. Wardlow, Martha C. Anderson, \& James P. Verdin (CRC Press/Taylor \& Francis, 2012).

This chapter is a U.S. government work and is not subject to copyright in the United States.

Authors:

\section{Justin Sheffield}

Department of Civil and Environmental Engineering

Princeton University

Princeton, New Jersey

\section{Youlong Xia}

Environmental Modeling Center

National Centers for Environmental Prediction

National Oceanic and Atmospheric Administration

Camp Springs, Maryland

\section{Lifeng Luo}

Department of Geography

Michigan State University

East Lansing, Michigan

\section{Eric F. Wood}

Department of Civil and Environmental Engineering

Princeton University

Princeton, New Jersey

\section{Michael Ek}

Environmental Modeling Center

National Centers for Environmental Prediction

National Oceanic and Atmospheric Administration

Camp Springs, Maryland

\section{Kenneth E. Mitchell}

Environmental Modeling Center

National Centers for Environmental Prediction

National Oceanic and Atmospheric Administration

Camp Springs, Maryland 


\section{North American Land Data Assimilation System A Framework for Merging Model and Satellite Data for Improved Drought Monitoring}

Justin Sheffield, Youlong Xia, Lifeng Luo, Eric F. Wood, Michael Ek, and Kenneth E. Mitchell

\section{CONTENTS}

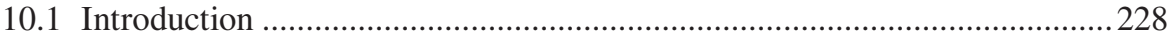

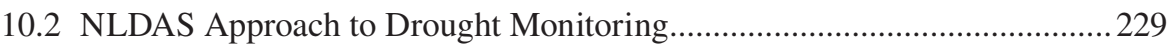

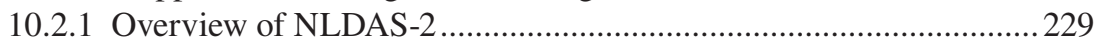

10.2.2 NLDAS-2 Models ................................................................ 230

10.2.3 Meteorological Forcings and Retrospective (1979-2007)

Simulation ....................................................................... 231

10.2.4 Drought Indices .................................................................... 231

10.3 Results from Retrospective Simulations.................................................... 232

10.4 NLDAS Drought Applications and Operational Aspects..............................237

10.4.1 NLDAS Real-Time Drought Monitoring.....................................2239

10.4.2 NLDAS Seasonal Forecasting …..................................................2239

10.5 Integration of New Remote Sensing Data into NLDAS

Drought Products............................................................................. 244

10.5.1 Microwave Soil Moisture Retrievals ..............................................246

10.5.2 Synergy with Other Remote Sensing Signals of Drought ............... 252

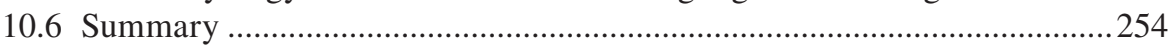

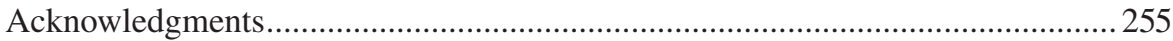

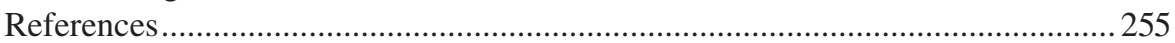




\subsection{INTRODUCTION}

Drought is a pervasive natural climate hazard that has widespread impacts on human activity and the environment. In the United States, droughts are billion-dollar disasters, comparable to hurricanes and tropical storms and with greater economic impacts than extratropical storms, wildfires, blizzards, and ice storms combined (NCDC, 2009). Reduction of the impacts and increased preparedness for drought requires the use and improvement of monitoring and prediction tools. These tools are reliant on the availability of spatially extensive and accurate data for representing the occurrence and characteristics (such as duration and severity) of drought and their related forcing mechanisms. It is increasingly recognized that the utility of drought data is highly dependent on the application (e.g., agricultural monitoring versus water resource management) and time (e.g., short- versus long-term dryness) and space (e.g., local versus national) scales involved. A comprehensive set of drought indices that considers all components of the hydrological-ecological-human system is necessary. Because of the dearth of near-real-time in situ hydrologic data collected over large regions, modeled data are often useful surrogates, especially when combined with observations from remote sensing and in situ sources.

This chapter provides an overview of drought-related activities associated with the North American Land Data Assimilation System (NLDAS), which purports to provide an incremental step toward improved drought monitoring and forecasting. The NLDAS was originally conceived to improve short-term weather forecasting by providing better land surface initial conditions for operational weather forecast models. This reflects increased recognition of the role of land surface water and energy states, such as surface temperature, soil moisture, and snowpack, to atmospheric processes via feedbacks through the coupling of the water and energy cycles. Phase I of the NLDAS (NLDAS-1; Mitchell et al., 2004) made tremendous progress toward developing an operational system that gave high-resolution land hydrologic products in near real time. The system consists of multiple land surface models (LSMs) that are driven by an observation-based meteorological data set both in real time and retrospectively. This work resulted in a series of scientific papers that evaluated the retrospective data (meteorology and model output) in terms of their ability to reflect observations of the water and energy cycles and the uncertainties in the simulations as measured by the spread among individual models (Pan et al., 2003; Robock et al., 2003; Sheffield et al., 2003; Lohmann et al., 2004; Mitchell et al., 2004; Schaake et al., 2004). These evaluations led to the implementation of significant improvements to the LSMs in the form of new model physics and adjustments to parameter values and to the methods and input meteorological data (Xia et al., 2012). The system has since expanded in scope to include model intercomparison studies, real-time monitoring, and hydrologic prediction and has inspired other activities such as high-resolution land surface modeling and global land data assimilation systems (e.g., the Global Land Data Assimilation System [GLDAS], Rodell et al., 2004; the Land Information System [LIS], Kumar et al., 2006).

The second phase of the project (NLDAS-2) extended the original concept (improved weather forecasting) in recognition of the value of the NLDAS products to the wider scientific community and stakeholders interested in hydrologic 
processes and data. A key part of this impetus was to provide water-related data to support water resources management, energy demand assessment, agricultural monitoring, fire risk assessment, drought monitoring, and flood prediction. In particular, the National Centers for Environmental Prediction (NCEP) Environmental Modeling Center (EMC) has collaborated with partners at the National Oceanic and Atmospheric Administration (NOAA) Climate Program Office (CPO) Climate Prediction Program of the Americas (CPPA) to develop an NLDAS drought monitoring and forecast system, which is the focus of this chapter. This system will provide a single stream of data that can be used for drought monitoring in support of the National Integrated Drought Information System (NIDIS; http://www.drought.gov), which is a federally mandated initiative to provide improved and consistent national drought information. Key characteristics of the NLDAS-2 drought products supporting this activity include improved reliability in model output demonstrated through rigorous LSM intercomparisons; the ability to detect the onset, extent, and duration of major drought events; the capability to perform long-term simulations so that robust climatologies can be calculated for meaningful anomaly detection; and rapid updating in near real time. To this end, the NLDAS-2 has focused on reducing the differences in calculated values among models and improving the representation of measured land fluxes and states to improve the reliability of the results. The project has also evaluated model depiction of major historic drought events over multiple decades to establish the consistency in the information and develop a reliable climatology, and demonstrated its use in an operational setting at the EMC. In addition, the system has been enhanced through the implementation of a seasonal forecasting component that has benefited from the improved land surface states that are essential to seasonal hydrologic prediction ( $\mathrm{Li}$ et al., 2009).

This chapter describes the development and application of NLDAS-2 products for drought monitoring and seasonal forecasting, as well as future challenges to improving the system. First, an overview of the long-term retrospective simulations in terms of their depiction of drought and highlights of some of the major drought events over the United States in the past 30 years are presented. Second, we explore how the models differ in their depiction of drought at various temporal and spatial scales, which relates to the reliability of the predictions. An overview of the realtime drought monitor and seasonal forecast systems is then provided with recent examples. Finally, we discuss the potential for augmenting the system with expanded use of remote sensing data. In particular, we assess the utility of remote sensingbased estimates of soil moisture for drought monitoring and discuss how they might be used in a model-based drought assessment such as the NLDAS to provide better predictions, for example, in regions with sparse precipitation measurement networks.

\subsection{NLDAS APPROACH TO DROUGHT MONITORING}

\subsubsection{Overview of NLDAS-2}

NLDAS-2 is a core project of the NCEP EMC funded by NOAA's CPPA with collaboration from several groups, including the National Aeronautics and Space Administration (NASA) Goddard Space Flight Center (GSFC), Princeton University, 
the National Weather Service (NWS) Office of Hydrological Development (OHD), the University of Washington, and NCEP's CPC. The system comprises three parts: a 28 year (1979-2007) retrospective simulation component that forms a climatology against which current conditions can be assessed, a real-time monitoring component that updates hydrologic fields daily, and a forecast component that makes seasonal forecasts on a monthly basis using ensemble (probabilistic) forecast techniques with lead times up to 6 months. Each of these components makes use of remote sensing data that are combined with ground observations and atmospheric model data to provide input data and boundary conditions for the LSMs. The remote sensing data include precipitation data, surface shortwave radiation, and vegetation spatial distribution and characteristics.

\subsubsection{NLDAS-2 MODELS}

The system incorporates four LSMs: the Noah, Mosaic, Variable Infiltration Capacity (VIC), and Sacramento (SAC) models. The Noah model was developed as the land component in the NOAA/NCEP mesoscale Eta model (Betts et al., 1997; Chen et al., 1997; Ek et al., 2003) and is the land model in the Weather Research and Forecasting (WRF) regional atmospheric model and the NOAA/NCEP coupled Climate Forecast System (CFS) and Global Forecast System (GFS) for short-term and medium-term weather forecasting, respectively. The Mosaic model was developed for use in the NASA global climate model (Koster and Suarez, 1994, 1996). The VIC model is a macroscale, semidistributed hydrologic model (Liang et al., 1994; Wood et al., 1997) that was developed at the University of Washington and Princeton University. The SAC model was developed as a lumped conceptual hydrologic model (Burnash et al., 1973), calibrated for small catchments and used operationally at NWS River Forecast Centers (RFC). It is run in a semidistributed mode for NLDAS. These models simulate the coupled water and energy cycles at the earth's surface at varying degrees of complexity. However, the SAC model only simulates the water cycle. Each model has unique attributes that reflect the origin of their development either as a hydrologic model or a Soil Vegetation Atmosphere Transfer (SVAT) model, intended to serve as the land component in atmospheric and climate models. For example, the VIC and Mosaic models use a unique tiling scheme to represent the heterogeneity of vegetation within a model grid cell. The Noah and SAC models use a single dominant vegetation type for each grid cell.

Each of these models is run over a common spatial domain on a regular 1/8th degree $(\sim 12 \mathrm{~km})$ grid that covers the conterminous United States, northern Mexico, and southern Canada $\left(125^{\circ}-67^{\circ} \mathrm{W}\right.$ and $\left.25^{\circ}-53^{\circ} \mathrm{N}\right)$. They share a common land mask, underlying elevation, hourly input surface meteorological forcing, soil texture, vegetation classes and distribution, streamflow network, streamflow routing model, and input and output file format. Common hourly output fields from each model include surface state variables such as soil moisture, soil temperature, snow water equivalent, surface fluxes (e.g., latent, sensible, and ground heat flux), and runoff. Although all models use common maps of vegetation and soil classes, they retain their unique soil and vegetation parameter values such as root depth and density, different soil column layering (number and thickness of layers), and different seasonal cycles of vegetation characteristics. The vegetation classification was derived from 
the University of Maryland Advanced Very High Resolution Radiometer (AVHRR)based data set of Hansen et al. (2000). All models specify the seasonality of vegetation on a climatological basis using AVHRR-based data. For Mosaic, SAC, and VIC, values of Leaf Area Index (LAI) and its seasonal cycle are derived from AVHRRbased Normalized Difference Vegetation Index (NDVI) data (Myneni et al., 1997). Noah uses the global, monthly 5 year climatology of the green vegetation fraction (GVF) derived by Gutman and Ignatov (1998) from AVHRR-based NDVI. Runoff and baseflow from each model are routed using a common river routing scheme (Lohmann et al., 2004) to produce streamflow at selected gauging points for comparison to measurements and analysis of flow characteristics.

\subsubsection{Meteorological Forcings and Retrospective (1979-2007) SimUlation}

The atmospheric forcings that drive the models are derived from a combination of data from atmospheric model reanalysis, ground measurements, and satellite remote sensing. The underlying data set comes from North American Regional Reanalysis (NARR; Mesinger et al., 2006) products with a $32 \mathrm{~km}$ spatial and $3 \mathrm{~h}$ temporal resolution. The data set includes $2 \mathrm{~m}$ (above the ground surface) air temperature, $2 \mathrm{~m}$ specific humidity, $10 \mathrm{~m}$ wind speed, surface pressure, precipitation, incoming solar radiation, and incoming longwave radiation. These are interpolated to the $1 / 8$ th degree $(\sim 12 \mathrm{~km})$ spatial resolution and $1 \mathrm{~h}$ temporal resolution of the NLDAS grid, accounting for changes in elevation and solar angle based on methods developed in NLDAS-1 (Cosgrove et al., 2003). Although the NARR improves on previous global reanalyzes in terms of its depiction of near-surface meteorology, especially through the assimilation of gauge precipitation data, some biases still remain, and for some variables (i.e., precipitation and downward surface shortwave radiation), observational data are used instead of the NARR. Precipitation is anchored to the CPC unified gaugebased precipitation analysis with orographic enhancements derived from Parameterelevation Regressions on Independent Slopes Model data (PRISM; Daly et al., 1994), with NARR precipitation data used in parts of Canada and Mexico where gauge density is low. The daily data are disaggregated to hourly time steps using groundbased Doppler radar data and remote sensing data from the NOAA CPC Morphing Technique (CMORPH) (Joyce et al., 2004). For shortwave radiation, a large bias in the NARR was removed by scaling it to match the remote sensing-based product of Pinker et al. (2003), which uses data from NOAA Geostationary Operational Environmental Satellites (GOES). Details of the NLDAS-2 forcings are given at http://www.emc.ncep.noaa.gov/mmb/nldas/LDAS8th/forcing/forcing_narr.shtml. The four models were run retrospectively for the period 1979-2007. Each model simulation was initialized from a "spin-up" simulation run for 1979-1995 so that the moisture and temperature states were brought to equilibrium.

\subsubsection{Drought INDICES}

As the full terrestrial water and energy cycles (except for the SAC model) are represented in the NLDAS, it is possible to depict drought in terms of any one or 
combination of hydrologic components such as precipitation, streamflow, and soil moisture. The NLDAS-2 real-time monitor provides a range of drought indices (see Section 10.4), including daily, weekly, and monthly anomalies, as well as percentiles of various hydrologic fields (soil moisture, snow water equivalent, total runoff, streamflow, evaporation, precipitation) output from the four LSMs on their common $1 / 8$ th degree grid.

Here we focus on soil moisture, given its role as an aggregator in the hydrologic system, reflecting precipitation and snowmelt inputs and the loss of water from the system via evapotranspiration, runoff, and drainage. Soil moisture forms the basis for improved short-term and seasonal weather prediction, through exertion of control over water and energy exchange with the atmosphere. Soil moisture fields can also be used for seasonal hydrologic prediction by providing antecedent states that are crucial to flood prediction, as well as future drought emergence. In this chapter, drought is shown in terms of monthly mean soil moisture percentiles, which normalize the data with respect to climatological values for each month at a 1/8th model grid cell resolution. This approach has been successfully used in model-based drought studies for the United States (Sheffield et al., 2004; Andreadis et al., 2005; Wang et al., 2009) and globally (Sheffield and Wood, 2007, 2008a; Wang et al., 2010) and in the assessment of drought under projected future climates (Sheffield and Wood, 2008b). The 20th percentile was chosen as the threshold for drought, which has been used in previous studies (Andreadis et al., 2005; Sheffield et al., 2009a), as well as in operational systems such as the U.S. and North American Drought Monitors (Lawrimore et al., 2002; Svoboda et al., 2002).

\subsection{RESULTS FROM RETROSPECTIVE SIMULATIONS}

We begin by providing an overview of historic drought as represented by the retrospective simulations from the four models. An essential element of drought monitoring is the background climatology to which current and future conditions can be compared and dry anomalies detected within an extended historical context. The use of multiple models helps to quantify the uncertainties due to model physics and parameterizations, but we also calculate a multi-model ensemble (MME) average that represents a best estimate of drought conditions given these model uncertainties. The multi-model average is calculated by averaging the percentiles of the four models and then recalculating percentile values with respect to the multi-model average, as the model averaging will tend to reduce extreme values (Wang et al., 2009, 2010).

Figure 10.1 shows soil moisture percentiles averaged over the continental United States and regionally for the multi-model average (calculated from the four NLDAS-2 LSMs). The regions are based on the NWS RFC regional delineations shown in Figure 10.2. In general, the spread among the models was very small, especially when averaged over the whole United States and for drier regions in the West (e.g., California-Nevada RFC). Despite the spin-up of the model states, there are still noticeable differences at the beginning of the time series (i.e., the first year, 1979), particularly for the drier western regions, where the model states used for the initial conditions may not have reached equilibrium. Although averaging over the United States smoothes the temporal variations in soil moisture time series, some 


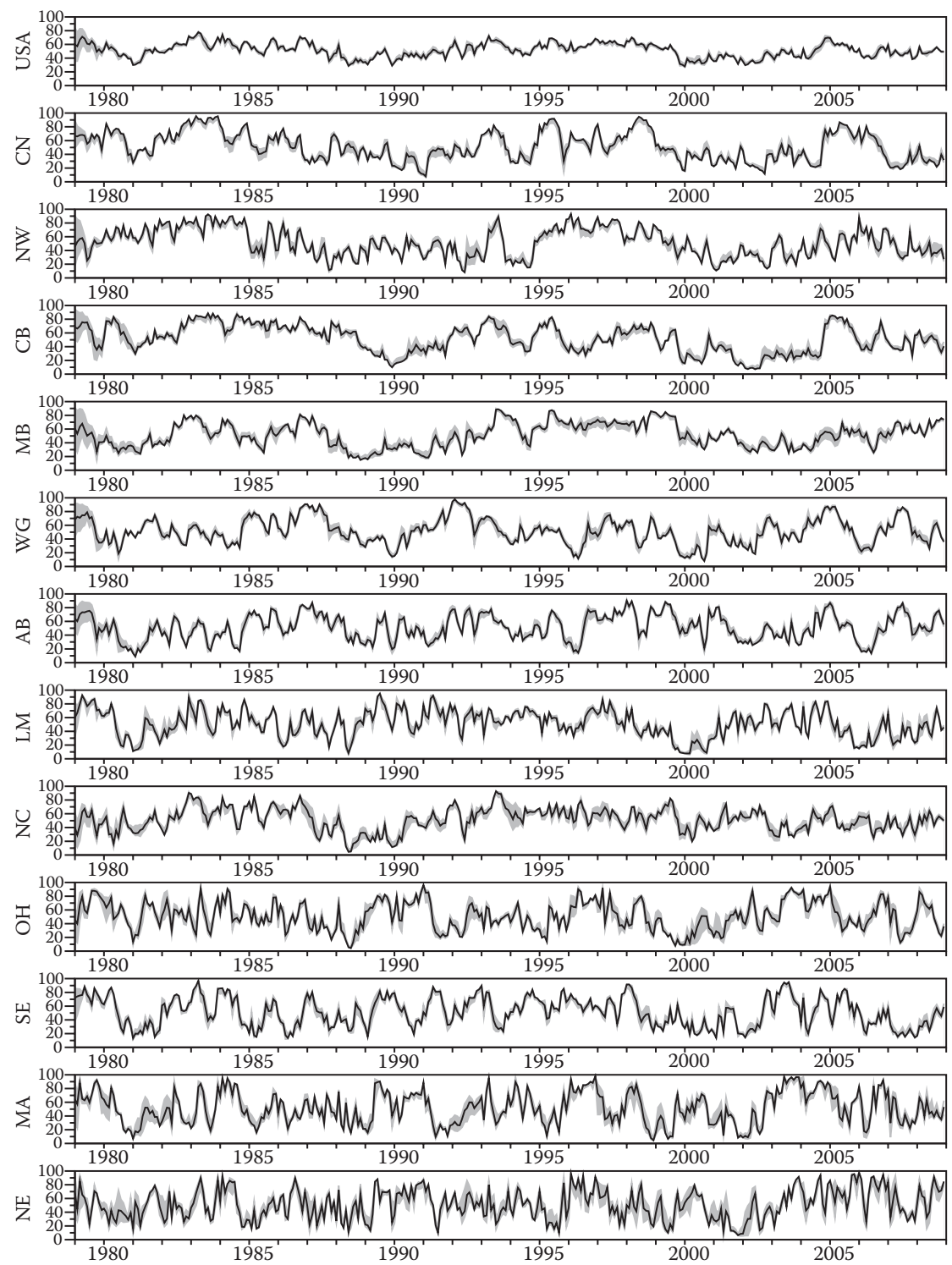

FIGURE 10.1 A 30 year time series (1979-2008) of soil moisture percentiles averaged over the continental United States and NWS RFC regions for the multi-model mean (calculated from the four NLDAS-2 LSMs). The gray shading represents the range in the models. The regions are ordered from west (upper panels) to east (lower panels).

periods in the early 1980s, late 1980s, and early 2000s are noticeably drier than normal, with large areas of drought within the regions during these periods (shown in Figure 10.3) based on a 20th percentile soil moisture threshold for drought. The peak areal percentage of the CONUS that is in drought for the MME is 54\% in June 1988. Regionally, the more humid eastern regions (bottom graphs) exhibited 


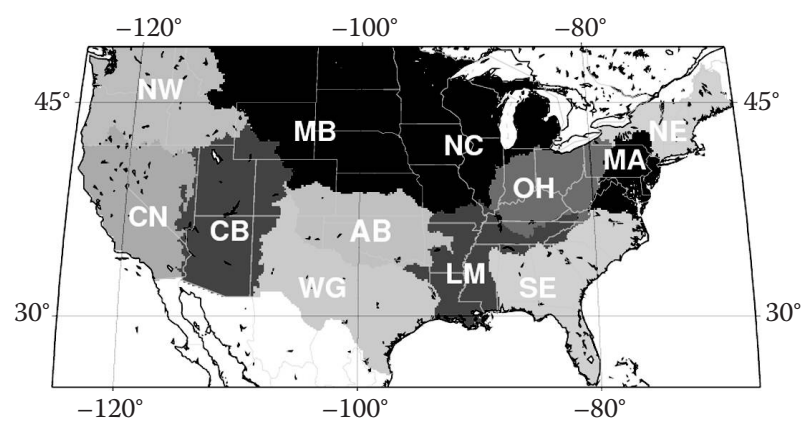

FIGURE 10.2 Map of the 12 continental U.S. RFC regions: Northwest (NW), Missouri Basin (MB), North Central (NC), Ohio Basin (OH), Northeast (NE), Middle Atlantic (MA), California-Nevada (CN), Colorado Basin (CB), Arkansas-Red Basin (AB), West Gulf (WG), Lower Mississippi (LM), and Southeast (SE).

greater variability than the drier western regions (upper graphs) and also had a larger spread among the model results. The largest differences among the models generally occurred during wet periods following a drought (e.g., during 2000 in the Ohio Basin (OHRFC) and during 2003-2004 in the Colorado Basin (CBRFC); Figure 10.2), which indicates that the differences are primarily derived from how each individual model partitions precipitation and propagates hydrologic anomalies through the system rather than how the models depict drying.

Figure 10.4 shows the spatial extent and severity of four major drought events in the United States (1988, 1996, 2002, and 2007) as simulated by the models and the MME. The 1988 drought spanned the central United States and northern Great Plains (Lawford, 1992; Trenberth and Branstator, 1992) and had the largest economic impacts of any drought or natural hazard in the United States, totaling $\sim \$ 39$ billion in losses (Riebsame et al., 1991) (only surpassed by Hurricane Katrina in total economic impacts), mainly because of its geographic extent over regions of high agricultural intensity (e.g., U.S. Corn Belt) and population density (e.g., eastern United States). This broad extent is well captured by the four models, as shown in Figure 10.4. The 1996 drought over Texas and parts of the Southwest resulted in estimated losses of \$6 billion in Texas alone (Wilhite, 2000). Again, the four models capture the broad pattern of the drought, but the differences between models can be large. For example, in northwestern Texas, the SAC model does not depict drought conditions, in contrast to the other models. The 2002 drought was part of a longterm drought in the western United States that had persisted since about 1999 but reached its peak areal extent during the summer of 2002, covering about $45 \%$ of the country, as indicated in the top time series graph in Figure 10.3. This is especially apparent for the Colorado Basin (CBRFC), where drought conditions covered more than $90 \%$ of the region, as defined by modeled soil moisture results in Figure 10.4. This drought was driven by near record low precipitation (Lawrimore and Stephens, 2003) and caused severe water resources impacts, with record low levels in the Lake Powell reservoir, increased wildfire hazards, and tree die-off directly attributed to drought and an associated insect outbreak (Betancourt, 2003). The more recent 

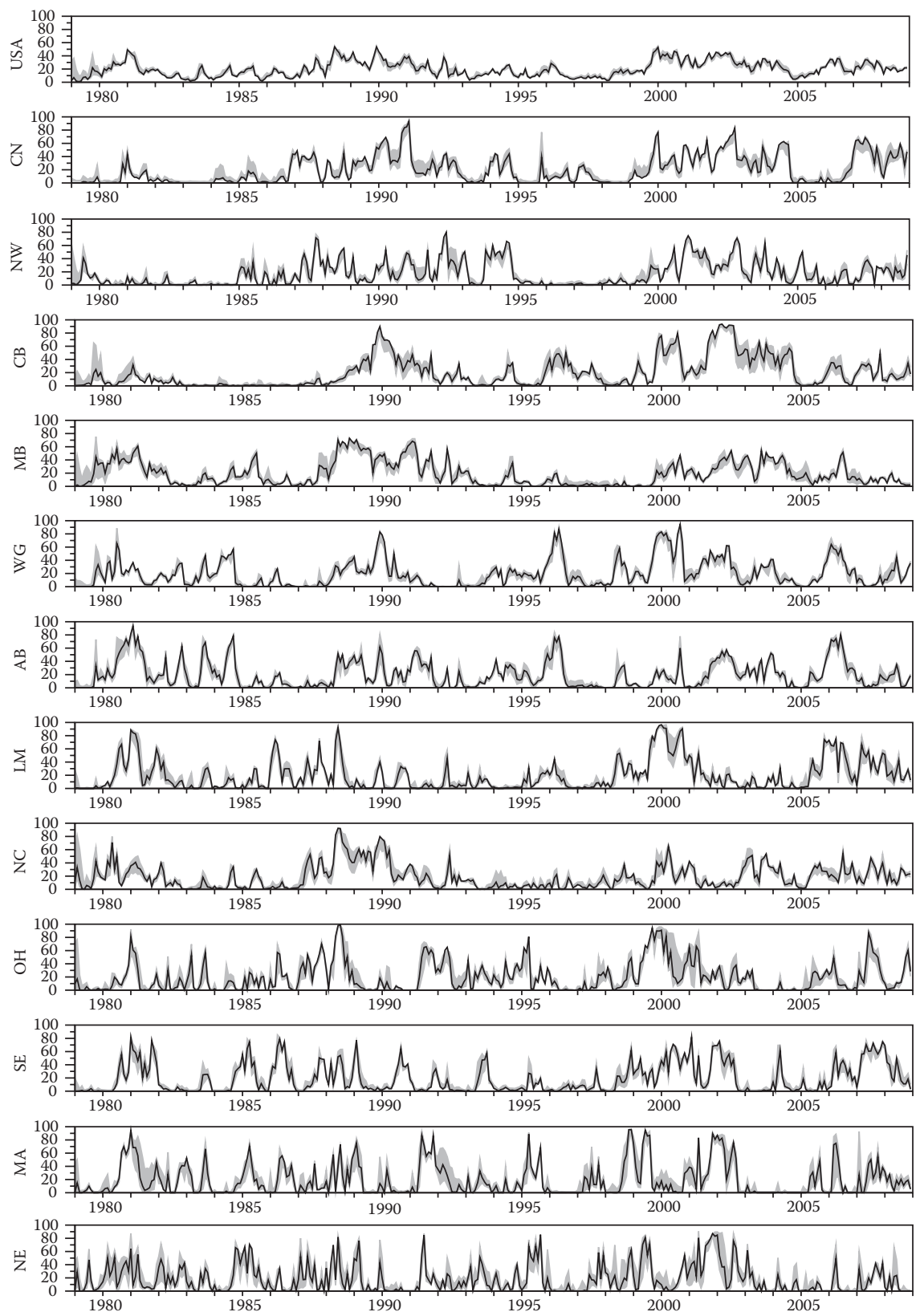

FIGURE 10.3 A 30 year time series (1979-2008) of the percentage of the total area of the continental United States and individual NWS RFC regions detected to be in drought from the soil moisture percentile information (drought defined as percentile $<20 \%$ ) for the multi-model mean (calculated from the four NLDAS-2 LSMs). The gray shading represents the range across the models. The regions are ordered from west (upper panels) to east (lower panels). 

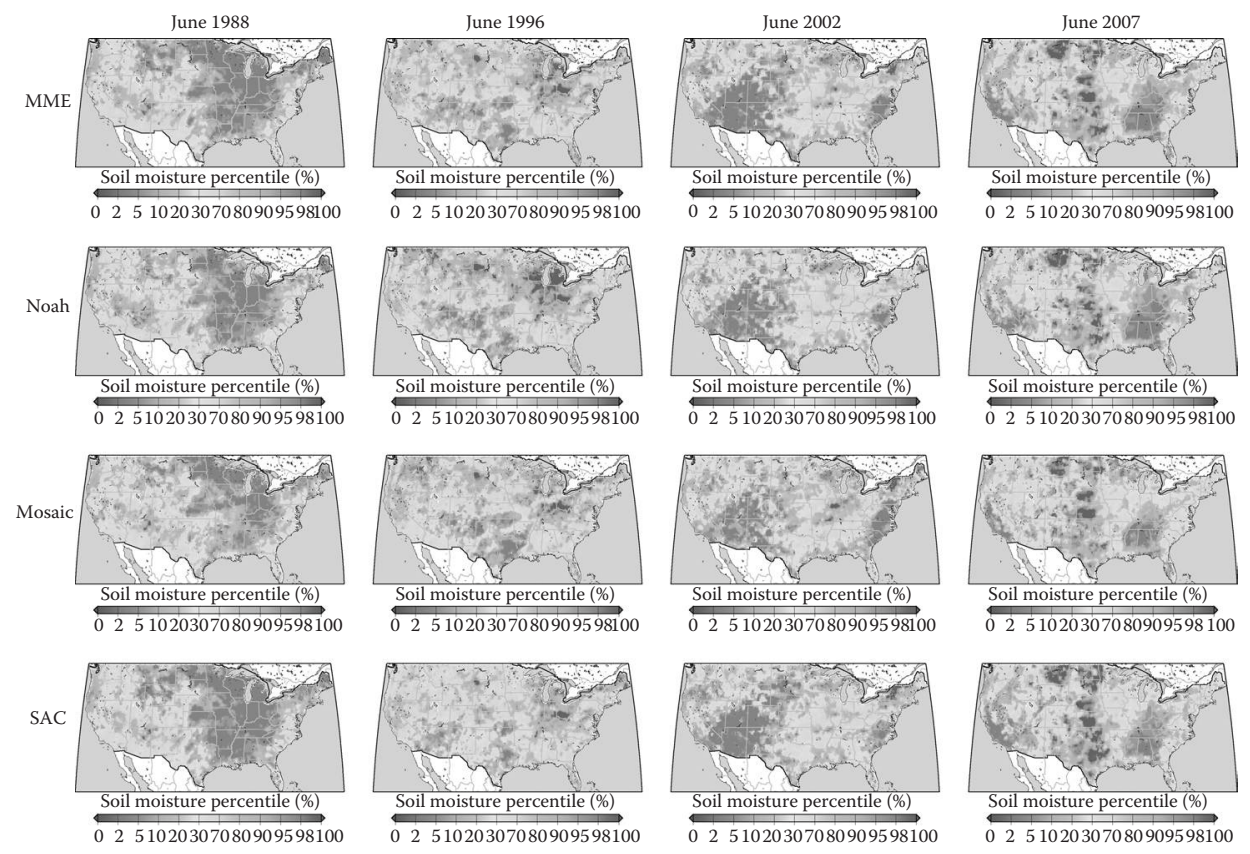

VIC
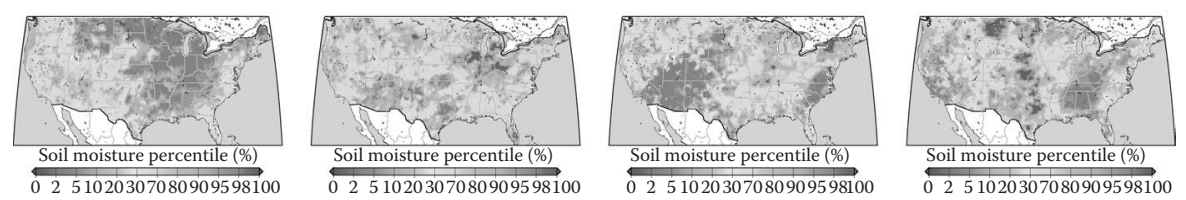

FIGURE 10.4 (See color insert.) Snapshots of four major drought events from June soil moisture percentiles from the MME and the four models. Columns are (1) 1988, (2) 1996, (3) 2002, and (4) 2007. 
2007 drought in the southeast United States reduced reservoir levels to record lows, affecting water supplies to the city of Atlanta and exacerbating interstate conflicts on water allocations. The model results in Figure 10.4 indicate that this drought covered the southern states to the east of the Mississippi River, while drought also affected California and other western states.

The four models produced remarkably consistent depictions of the peak extent of these large-scale drought events, indicating that their rank correlations are high. They also agree well on the location and magnitude of wet regions. Some level of agreement is to be expected among the models given the commonality in the meteorological forcings and underlying land surface characteristics, as well as the use of percentiles for quantifying drought severity. Nevertheless, the level of intermodel consistency is encouraging, and the classified drought patterns appear to coincide with the known extents and impacts of these major events as discussed earlier.

However, as we look at local scales and the overall statistics of soil moisture deficits, the differences between the models become more apparent. Figure 10.5 shows the statistics of the duration and frequency of soil moisture deficits on a grid cell basis for the four models. As before, deficits are defined as soil moisture below the 20th percentile lasting for one or more months and are referred to as a run (Yevjevich, 1972). This is a somewhat loose definition of drought, but it reveals the differences in the timescales of soil moisture variation between the models. The SAC model has the highest number of deficits of any duration; this in part is driven by the higher frequency of short-term runs (1-3 months) and lower frequency of long-term runs ( $>12$ months), and is reflected by the lower mean duration. In contrast, the Mosaic model has the lowest total number of runs, lowest number of short-term runs, and highest number of long-term runs. The VIC and Noah models have similar statistics, although the Noah tends to have longer duration runs and a sharper delineation between regions, with high short-term frequencies in the east and northwest and high long-term (>12 months) frequencies in the west. These differences are related to the variability of soil moisture in each of the models, which can vary considerably (Schaake et al., 2004) across models and climate regimes because of differences in model parameterizations of soil water movement and the relationships to soil water drainage and infiltration. Although the models agree well at large scales, there are significant differences at the shorter time steps and in the local-scale spatial patterns, which affect how the depicted drought develops, persists, and recovers, with ramifications for regional- and local-scale monitoring. This highlights the value of an MME for reducing the impacts of model-specific parameterizations.

\subsection{NLDAS DROUGHT APPLICATIONS AND OPERATIONAL ASPECTS}

One rationale for running NLDAS-2 is to support operational drought monitoring and seasonal drought forecasting. To this end, the NLDAS is now producing real-time information and future predictions of the hydrologic cycle across the United States, including drought monitoring products and seasonal drought forecasts. The NLDAS-2 drought monitor provides daily updates at 1-2 days behind real time, and the seasonal forecast system makes predictions every 
Noah

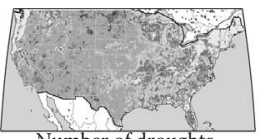

(a)

(b)

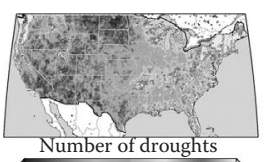

$\begin{array}{llllll}0 & 5 & 10 & 15 & 20 & 25\end{array}$

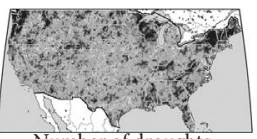

(c)

(d)

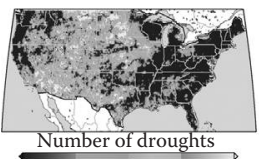

$\stackrel{2}{0}$

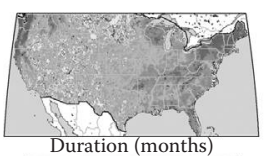

(e) $\underset{012345678910}{\longrightarrow}$
Mosaic

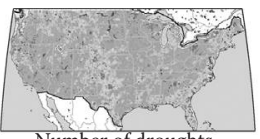

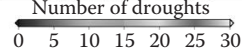
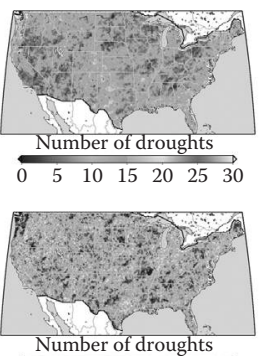

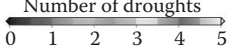
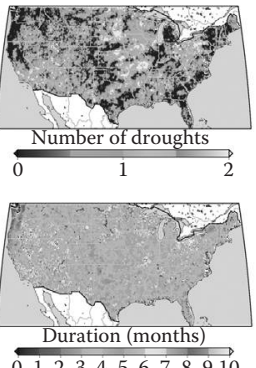

SAC

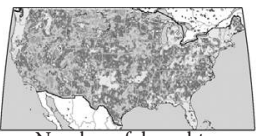

$\stackrel{\text { Number of droughts }}{\stackrel{5}{0}}$

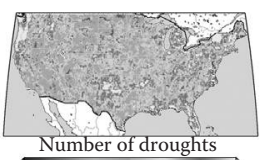

5 10 $15 \quad 20 \quad 2530$

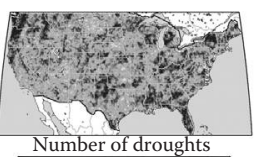

0 \begin{tabular}{lllll} 
Number of droughts \\
\hline
\end{tabular}
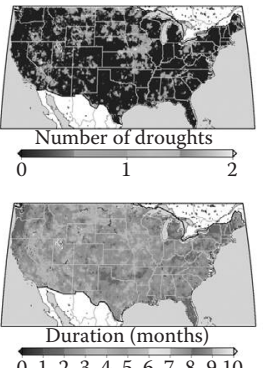

VIC

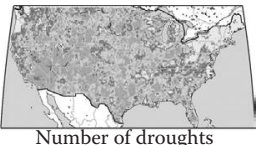

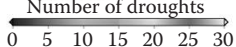
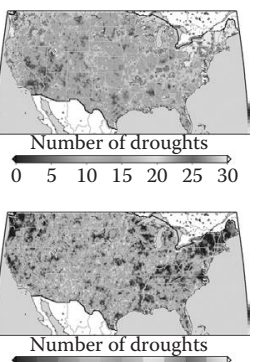

\begin{tabular}{llllll}
\hline 0 & 1 & 2 & 3 & 4 & 5
\end{tabular}
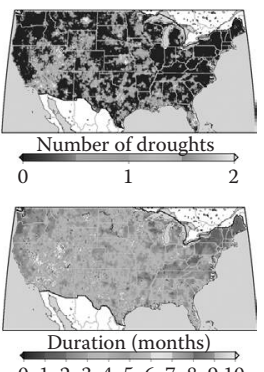

FIGURE 10.5 (See color insert.) Statistics of drought duration and frequency for the four LSMs for 1979-2008 calculated from monthly soil moisture percentiles. A drought is defined at each grid cell when the soil moisture percentile drops below 20\%. (a) Total number of droughts, (b) number of short-term (1-3 month duration) droughts, (c) number of medium-term (7-12 month duration) droughts, (d) number of long-term (>12 month duration) droughts, and (e) the mean drought duration. 
month out to 9 months into the future. These products are provided to the community at http://www.emc.ncep.noaa.gov/mmb/nldas/. The near-real-time forcing data and output from the models are available in hourly time step in binary compressed GRIB2 format files and can be accessed from the NCEP EMC via ftp (ftp://hydro1.sci.gsfc.nasa.gov/data/s4pa/NLDAS) and from the GES DISC GrADS Data Server (http://hydrol.gsfc.nasa.gov/dods/).

\subsubsection{NLDAS Real-Time Drought Monitoring}

The NLDAS experimental drought monitor is based on near-real-time output of soil moisture and other hydrologic variables from the four LSMs, thus providing an MME estimate of current drought conditions across the United States. The anomalies and percentiles are based on a 28 year climatology (1980-2007). Two separate climatology files are used, one for the calculation of anomalies and the other for the calculation of percentiles. Anomalies are calculated by comparing the current soil moisture values to mean values for the same time of year over each grid cell. Percentiles are based on a 5 day moving window of soil moisture values. This acts to smooth out the soil moisture record and removes any high frequency variations (or noise) in the data. Weekly analyses for each grid cell are computed by comparing the past 7 days to the corresponding period in the percentile climatology. Taking day 1 of the week as an example, hourly soil moisture values from this day are averaged together to form a single daily value. This value is then ranked against the soil moisture values from each day of the 5 day window surrounding day 1 of the corresponding week in the percentile climatology. This same process is then repeated for days 2-7 of the week, with each day of the week contributing equally to the overall ranking value. Monthly (30 day) percentile analyses are computed in a similar fashion. Figure 10.6 shows an example of the real-time monitor for the MME from December 2010 for precipitation, evapotranspiration, runoff, streamflow, soil moisture, and snow water equivalent. Comparison of the anomalies shows drier than normal conditions in the Gulf Coast states, with particularly dry conditions in east Texas and Louisiana, yet there are striking differences between the different hydrologic components, highlighting the differences in how anomalies propagate through the system. Collectively, these differences would be expected, given that different components of the hydrologic system respond at varying temporal intervals to moisture deficits ranging from days to weeks for precipitation, ET, and soil moisture to weeks to months for streamflow. As a result, each of these NLDAS-2 products has the potential to provide useful information about specific hydrologic components that could enhance hydrological drought monitoring.

\subsubsection{NLDAS Seasonal Forecasting}

The experimental seasonal hydrologic forecast systems of Luo and Wood (2008) and Wood and Lettenmaier (2006) have been combined and applied to the NLDAS suite of models and data products to form the NLDAS-2 seasonal hydrologic 

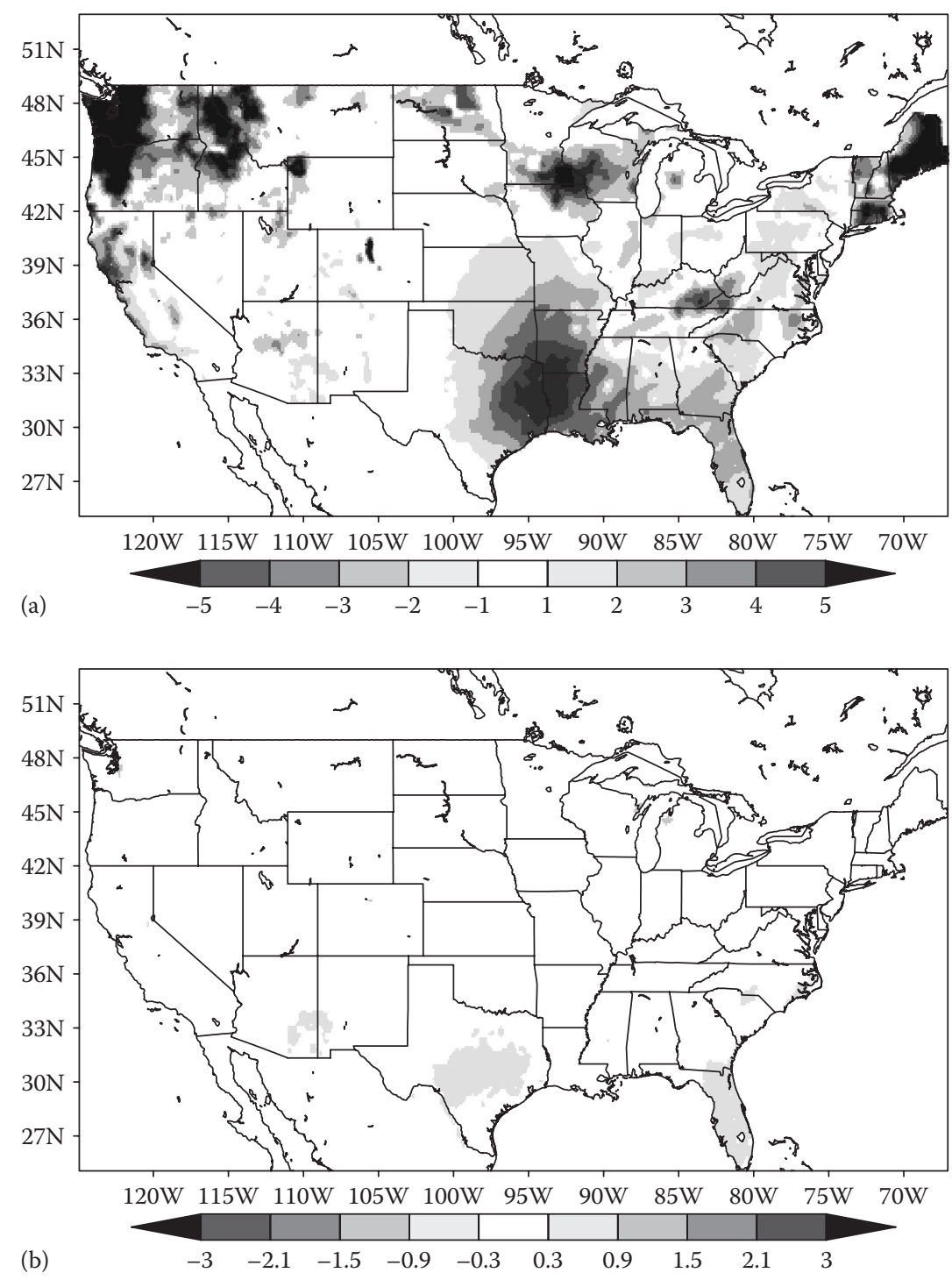

FIGURE 10.6 (See color insert.) Example of output fields from the NLDAS-2 drought monitor (http://www.emc.ncep.noaa.gov/mmb/nldas/drought/), showing anomaly data for the week ending on December 16, 2010, for (a) precipitation and multi-model averages of (b) evapotranspiration, 

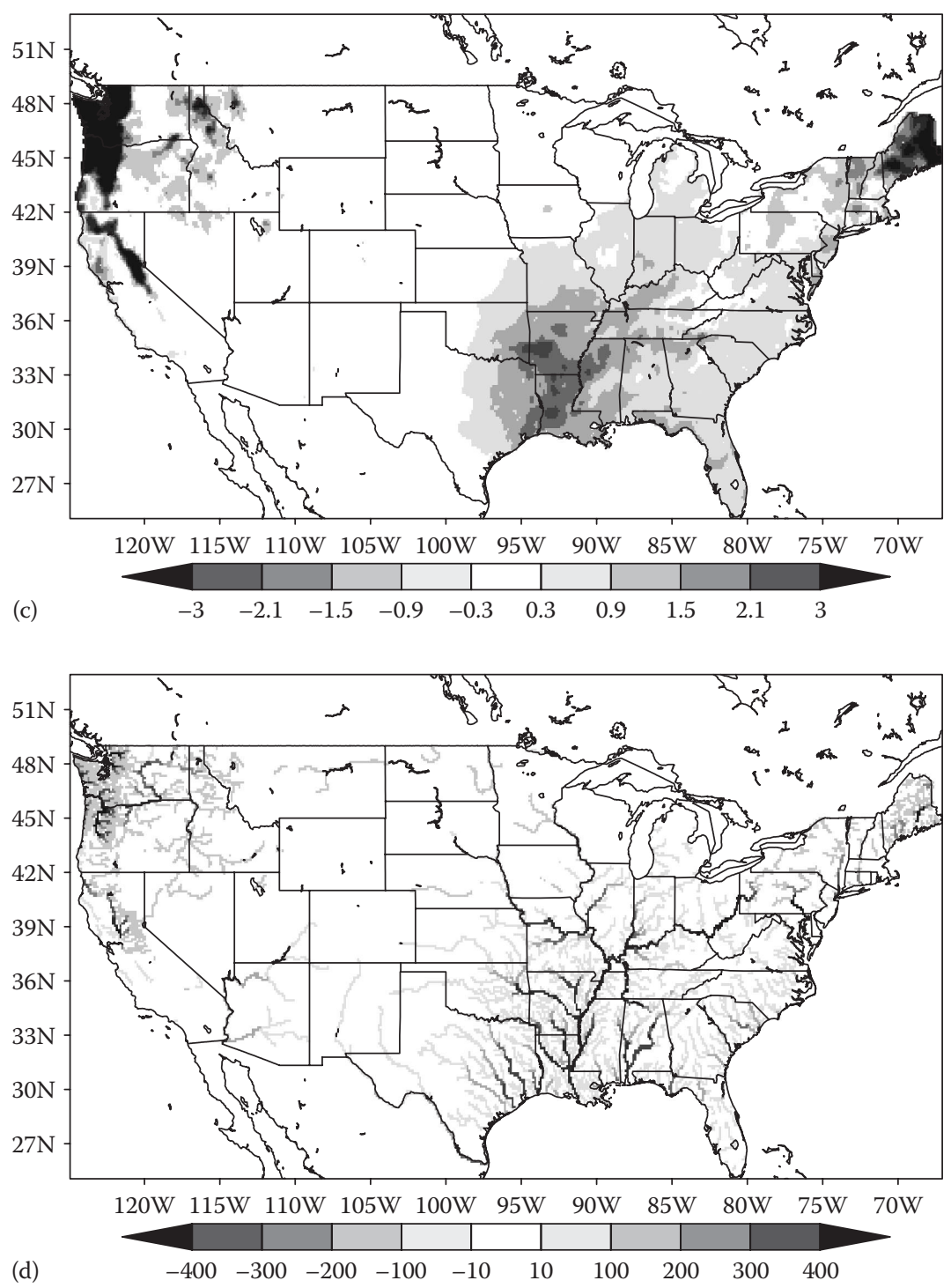

FIGURE 10.6 (continued) (See color insert.) (c) runoff, (d) streamflow, 

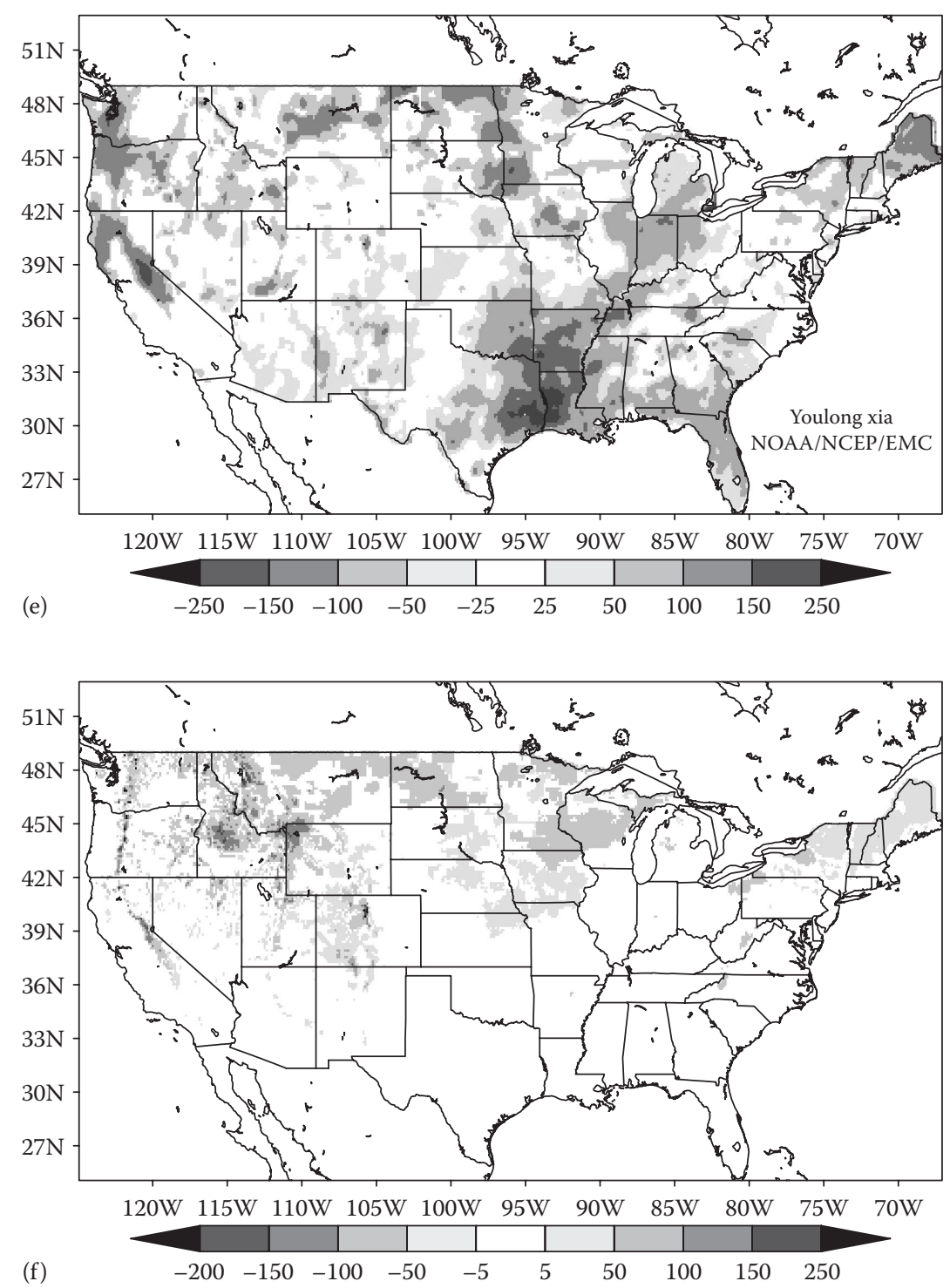

FIGURE 10.6 (continued) (See color insert.) (e) soil moisture, and (f) snow water equivalent.

forecast system. Currently, only the VIC model is used in the experimental forecast, with plans to incorporate the other models in the future. Forecasts are produced monthly at the beginning of each month using the initial condition that is closest to the first day of the month. Three forecast approaches are implemented that depend on the source of the climate forecast data from either statistical or dynamical forecasts. The climate data are then downscaled to $1 / 8$ th degree, bias 
corrected, and used to drive the VIC model to produce predictions of hydrology and drought conditions. The three forecast approaches are

1. The CFS-based forecast (Saha et al., 2006) uses seasonal forecasts from the NCEP CFS dynamical model. The set of CFS forecasts from the previous month are combined to form the model forecast distribution, which is then merged with historic observations using a Bayesian approach developed by Luo et al. (2003) and Luo and Wood (2008).

2. The CPC outlook-based forecast (http://www.cpc.ncep.noaa.gov/products/ forecasts/) is based on expert merging of statistical and dynamical (including CFS) forecasts and is generally comparable in skill to the CFS-only forecasts. It uses the seasonal outlook of probability of exceedance (POE) released by the NCEP CPC during the previous month as the forecast distribution for each of the 102 U.S. climate divisions. These distributions are applied to all NLDAS grid boxes within the climate division.

3. The Extended Streamflow Prediction (ESP) (Day, 1985) method is based on resampling of the historic record, and therefore, its skill will generally not exceed that of the other two methods. The ESP method uses 20 randomly selected historical atmospheric forcing time series as possible realizations of future conditions. To be comparable and practical, both CFS and CPC outlook-based approaches also generate 20 ensemble members.

Figure 10.7 shows forecasts made in March 2010 using the three methods. Each column is the 6 month forecast from one forecast approach, and each row is the specific forecast for each individual month, showing the probability of drought persisting at lead times of 1-6 months, where drought is defined by monthly average soil moisture percentiles and a 20th percentile threshold. Given that the NLDAS-2 seasonal forecast system is an ensemble forecast system, the drought forecast includes a forecast anomaly, forecast percentile, and forecast probability analysis. The anomaly and percentile of the ensemble mean or median are used as a single-valued deterministic forecast. When interpreting the ensemble forecast in a probabilistic fashion, the probability of drought (when soil moisture is below 20th percentile) is derived from the ensemble. More details of the system and development history can be found on the Princeton Seasonal Hydrological Forecast System website (http://hydrology.princeton.edu/forecast).

The drought forecast system has been evaluated with respect to hindcasts of the 1988 drought and also tested in real time for the 2007 drought in the southeast United States. Figure 10.8 shows the drought forecast made on January 1, 2007, for the subsequent 3 months compared to the drought conditions estimated later from the observation-forced monitoring that represents our best estimate of true conditions. In this case, the system was able to forecast the development of drought conditions in California (with low uncertainty as represented by the ensemble spread) and in the southeast (with larger uncertainty in the magnitude and location of the drought center) up to 3 months in advance. In general, the system has demonstrated significant skill in the first 2 months of a forecast and shows marginal skill out to 4-6 months (Luo and Wood, 2008). 


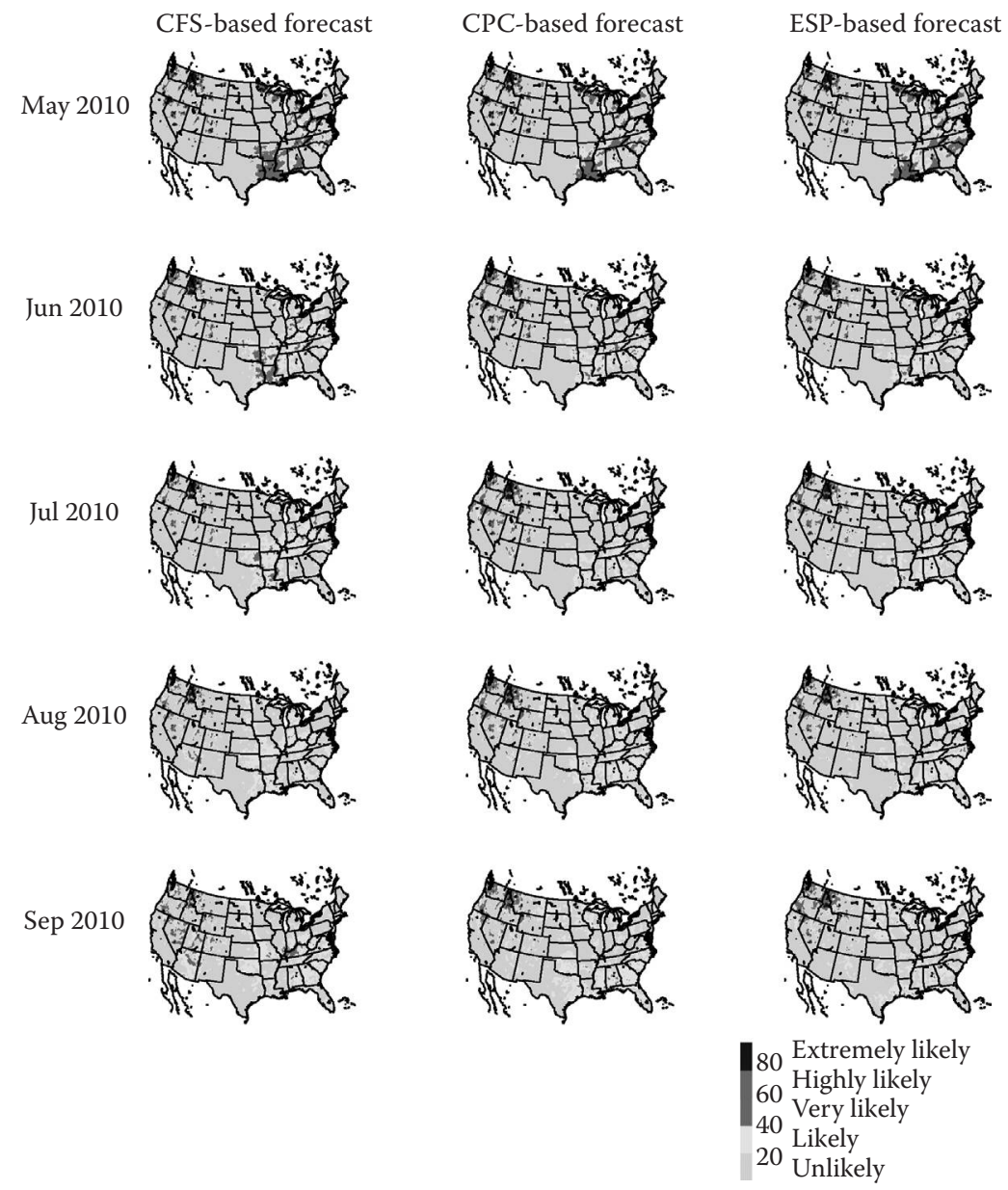

FIGURE 10.7 (See color insert.) Example of seasonal forecasts for May through September 2010, showing the likelihood of drought developing or persisting at lead times of 1-6 months. A drought is defined as soil moisture deficits below the 20th percentile, and the likelihood is based on ensemble forecast distributions. Forecasts are based on three methods: (1) CFS, (2) CPC official outlooks, and (3) ESP.

\subsection{INTEGRATION OF NEW REMOTE SENSING DATA INTO NLDAS DROUGHT PRODUCTS}

The NLDAS framework provides a mature platform for producing real-time fields of hydrologic variables in support of drought monitoring and as initial conditions for seasonal drought forecasting. These products have been evaluated through a series of studies that began with NLDAS-1 (e.g., Sheffield et al., 2003; Lohmann et al., 2004; Schaake et al., 2004) through more recent studies within NLDAS-2 (e.g., Xia et al., 2012) as presented in Section 10.3, which show that consistent depictions of large-scale historic drought events were characterized within this system. Nevertheless, a number 

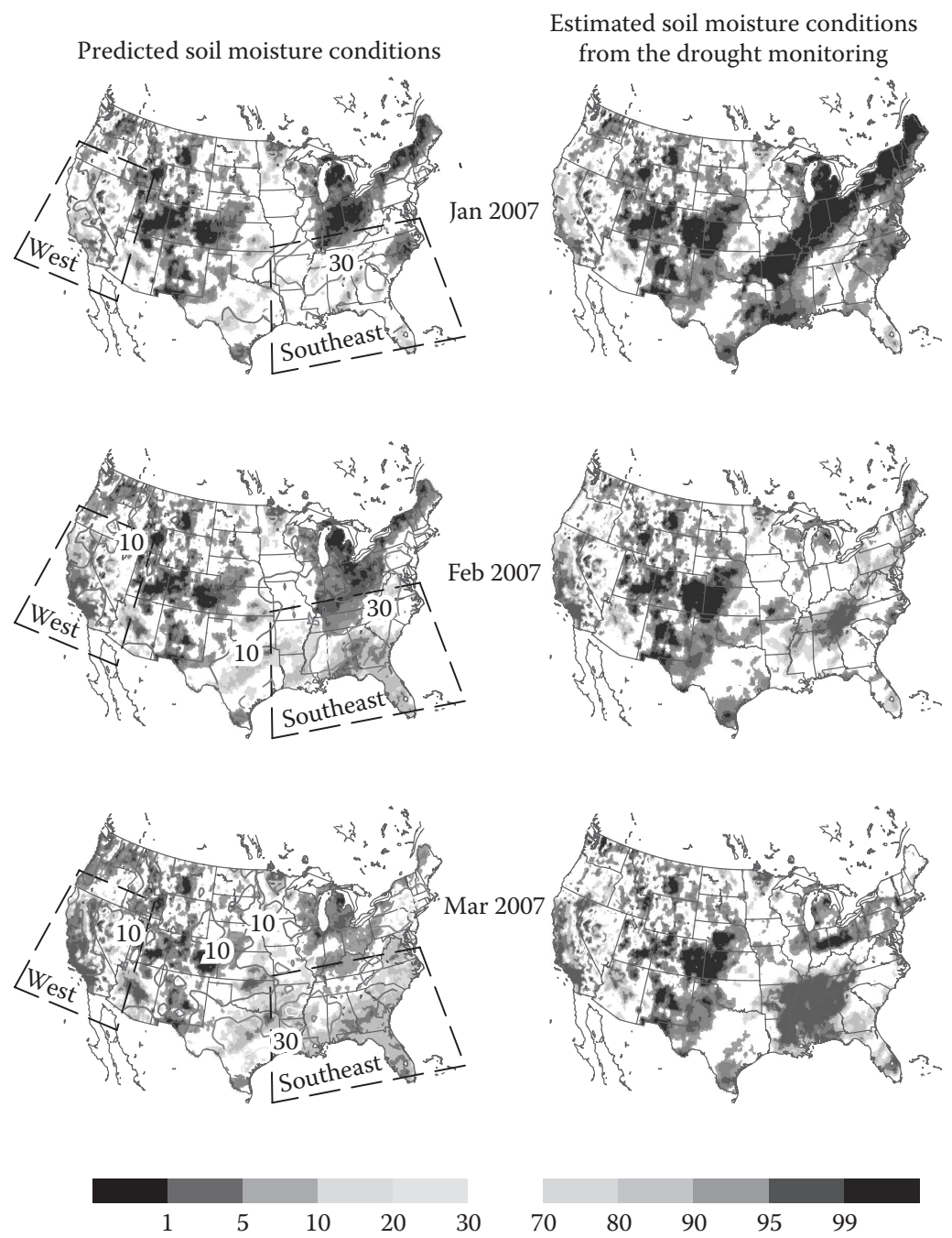

FIGURE 10.8 (See color insert.) Example of seasonal prediction of the 2007 U.S. drought (figure reproduced from Luo L. and E.F. Wood, Geophys. Res. Lett., 34, L22702, 2007). Predictions of soil moisture percentiles (\%) (left column) were made starting on January 1, 2007, using downscaled and bias-corrected CFS seasonal climate forecasts to drive the VIC model, and are compared to estimated soil moisture from the real-time drought monitoring (right column). Left column shows the mean of the most likely ensemble set (shaded) and their spread (contour). The boxes indicate regions where drought was most severe during early 2007.

of challenges remain, and improvements can be made, including understanding the differences in how each model represents the dynamics of drought development (as motivated by the large differences in drought statistics shown in Section 10.3) and improving the accuracy of the monitoring, especially in regions with few meteorological ground stations. The use of satellite-based remote sensing data can greatly benefit monitoring over areas with a sparse gauge network and at high elevations where there 
is high spatial variability in meteorological conditions. Remotely sensed observations provide exceptional spatial coverage at a relatively high temporal sampling interval over large areas where quality in situ data are limited. Currently, NLDAS-2 uses GOES-based downward solar radiation as a forcing and AVHRR data to parameterize the spatial and seasonal variation in vegetation. In this section, we explore the potential for integrating new sources of remote sensing data, specifically using remotely sensed data to estimate soil moisture, groundwater, and precipitation, which can be used to enhance NLDAS drought monitoring and prediction across the United States.

\subsubsection{Microwave Soll Moisture Retrievals}

Much progress has been made in recent years in retrieving terrestrial water cycle variables from space (Tang et al., 2009), and it is now possible to monitor all components, albeit with uncertainty and nonclosure of the water budget (Sheffield et al., 2009b). Nevertheless, it is possible to use these products to detect changes in moisture availability and the presence of drought. For soil moisture, long-term (decadal) products that merge information across satellites and sensors are being produced (e.g., Owe et al., 2008) and real-time products are available (e.g., Njoku et al., 2003). Remotely sensed soil moisture can be used in a number of different ways to improve drought monitoring: as a direct complement to in situ observations and modeled data, as well as through assimilation into LSMs. This can help in regions where gauges are sparse or where radar incorrectly identifies precipitation because of evaporation or advection before it hits the ground (McCabe et al., 2008). However, several challenges in using remotely sensed soil moisture data limit their use and dictate how they should be employed. For example, microwave soil moisture retrievals directly sample soil moisture conditions only in the top few $\mathrm{cm}$ of the soil profile and can be obtained only at relatively coarse spatial resolution $(25-40 \mathrm{~km})$ under relatively sparse vegetation cover.

Soil moisture can be retrieved at large scale (but coarse resolution) using satellite-borne passive and active microwave sensors. Various emission sources combine to provide the microwave brightness temperature (BT) that the satellite observes. Radiation is received from the atmosphere, vegetation, and the top layer of the soil, which is dependent on the moisture content via the sensitivity of the soil emissivity. Although BT is sensitive to soil moisture, these other sources of emissions must be taken into account. These sources can be modeled using a radiative transfer model, and a soil moisture value can be inferred with a $1 \mathrm{~K}$ change in BT roughly equivalent to a $2 \%$ change in soil moisture, depending on the microwave frequency. Several satellite-based microwave sensors have been used for retrieving soil moisture, including the Tropical Rainfall Measurement Mission (TRMM) Microwave Imager (TMI) on the NASA TRMM satellite, which was launched in 1997, and the Advanced Microwave Scanning Radiometer on the Earth Observing System (AMSR-E) aboard the NASA Aqua satellite that was launched in 2002. The biggest drawback of these current active radiometers is the emission depth of the microwave signal, which is dependent on the wavelength and is generally restricted to the top centimeter of soil. For drought applications, the primary interest is the integrated soil moisture over a greater depth (ideally the root zone) than the top centimeter. Soil moisture varies greatly vertically, and as a result, soil moisture conditions at a shallow soil depth may 
bear little resemblance to conditions in the total soil column. It is challenging to use soil moisture information estimated from these satellite-based systems to identify drought and to compare with data from (or when assimilating into) LSMs, which typically have top soil layers on the order of $5-10 \mathrm{~cm}$ or more.

In densely vegetated regions, the microwave signal from the underlying soil is attenuated, and the vegetation itself emits a signal, complicating the estimation of soil moisture from the satellite measurements. This generally results in retrievals being restricted to sparsely vegetated regions characterized by low vegetation biomass and water content. Current passive microwave sensors are generally in the C-band (4-8 GHz) (AMSR-E at $6.9 \mathrm{GHz})$ or $\mathrm{X}$-band $(8-12 \mathrm{GHz})$ range (TMI and AMSR-E at $10.7 \mathrm{GHz})$, although L-band $(1-2 \mathrm{GHz})$ is much better in terms of lower attenuation through vegetation and a deeper effective soil emission depth. Figure 10.9 shows the regions of microwave-based soil moisture retrievability across the United States based on estimated vegetation water content for X-and L-band microwave radiometers. The upper limit for X-band
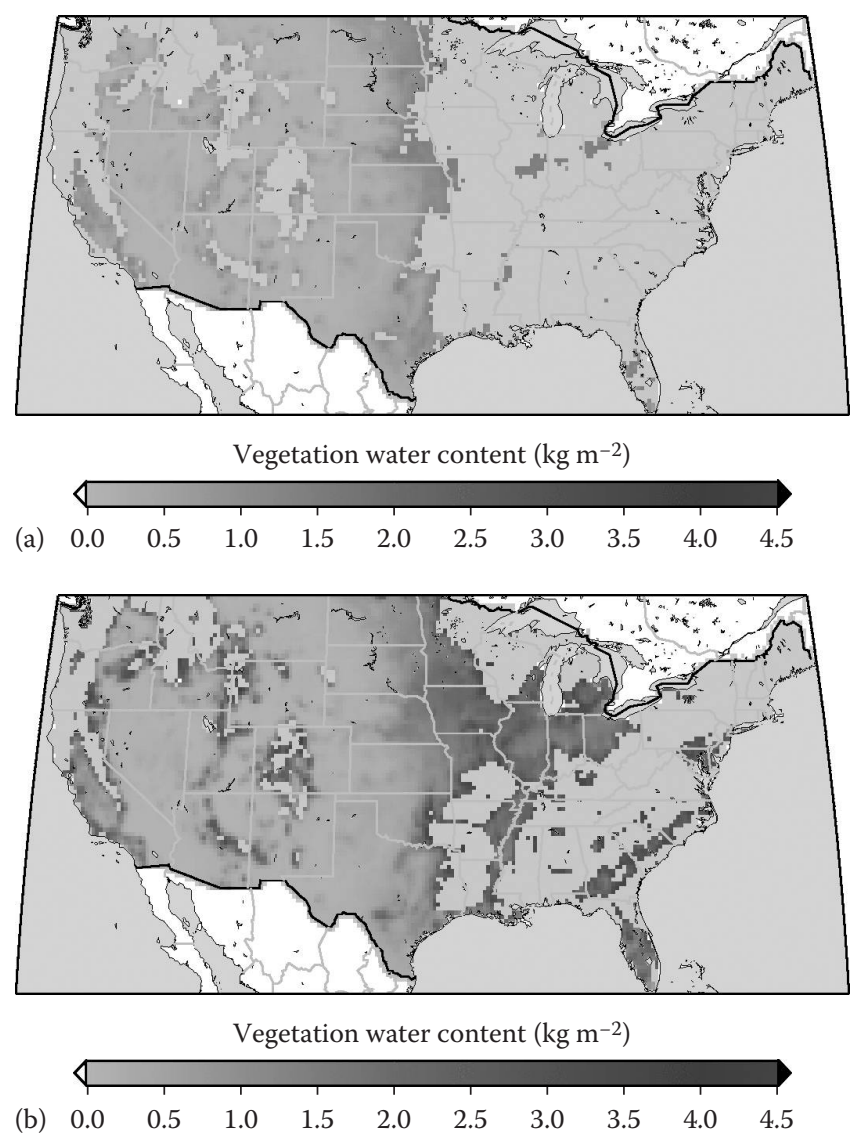

FIGURE 10.9 (See color insert.) Zones of applicability for microwave remote sensing retrievals of soil moisture based on penetration through vegetation for frequencies in (a) X-band $(10.7 \mathrm{GHz})$ and (b) L-band $(1.4 \mathrm{GHz})$. Vegetation is characterized by its vegetation water content $\left(\mathrm{kg} \mathrm{m}^{-2}\right)$. Gray shading indicates areas where retrievals of soil moisture are not feasible. 
$(10.7 \mathrm{GHz})$ retrievals is $1.5-2 \mathrm{~kg} / \mathrm{m}^{2}$ (Njoku et al., 2003; Narayan et al., 2004) and for L-band $(1.4 \mathrm{GHz})$ retrievals is $4-5 \mathrm{~kg} / \mathrm{m}^{2}$ (Kerr, 2007). As a reference, short grass is less than $1 \mathrm{~kg} / \mathrm{m}^{2}$; corn and soybeans can be up to 6 and $1-3 \mathrm{~kg} / \mathrm{m}^{2}$, respectively. There is a clear delineation in the middle of the United States in the zones of feasible soil moisture retrievals at $10.7 \mathrm{GHz}$ (Figure 10.9a). For an L-band instrument, the extent of feasible zones expands as signals can penetrate higher vegetation water contents (Figure 10.9b). Despite this expanded geographic coverage, retrievals are still not possible in many areas, particularly in the densely vegetated eastern United States.

The spatial resolution of satellite-based microwave data, generally on the order of $40 \mathrm{~km}$, is also a limiting factor even though data products are often provided at a higher $25 \mathrm{~km}$ spatial resolution because of oversampling. Because of the high spatial variability of soil moisture at a local scale, interpretation of $25-40 \mathrm{~km}$ data can be problematic. Landscapes can comprise many different land covers, often in complex spatial patterns, which results in the integration of emissions from multiple land cover surfaces at the coarse pixel level that may be contaminated by signals from water bodies and/or dense vegetation, resulting in unrepresentative soil moisture estimates. The presence of water bodies or dense vegetation will tend to give overestimates of soil moisture. This has obvious consequences when comparing to a point-based observation from a soil moisture probe or trying to infer soil moisture at subpixel scales. Other factors that hinder the retrievals include the presence of active precipitation, snow, and frozen soils. Current research is looking to combine products from multiple microwave satellite sensors to improve spatial and temporal coverage and resolution, including combining passive and active products (Das et al., 2011; Liu et al., 2011). However, these are generally still restricted to higher frequencies in the X-band because the C-band suffers from radio frequency interference (RFI) and cannot retrieve soil moisture over dense vegetation. The recently launched European Space Agency (ESA) Soil Moisture Ocean Salinity (SMOS) mission and the future planned NASA Soil Moisture Active and Passive (SMAP) mission will carry L-band instruments, which will increase temporal sampling and improve the effective emission depth to about five times deeper into the soil than the current TMI and AMSR-E $\mathrm{X}$-band radiometers, which should provide better soil moisture estimates that are representative of deeper soil moisture conditions (Entekhabi et al., 2008).

Although there are challenges in determining where soil moisture can be retrieved from satellite-based microwave observations and how to interpret the values, the potential exists to use these data within a drought monitoring framework such as NLDAS-2. Figure 10.10 compares soil moisture retrievals from AMSR-E over the United States from 2002 to 2008 with NLDAS-2 model output. The retrieval is derived from AMSR-E BTs using the Princeton Land Surface Microwave Emission Model (LSMEM; Drusch et al., 2004). The model uses surface properties such as vegetation water content and soil texture and also the land surface states of temperature and soil moisture to estimate the top of atmosphere (TOA) BT that the satellite sensor would record. To estimate soil moisture from an actual satellite-observed BT, the model is run in "forward" mode by iterating over soil moisture values until the modeled BT matches the satellite observation. Figure 10.10a shows the range in soil moisture for all months over the full 7-year period and indicates that the largest sensitivity of the soil moisture retrievals is in the central United States. This sensitivity 


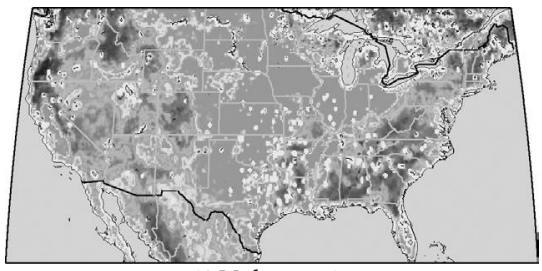

$\%$ Volumetric

(a) 05101520253035404550556065

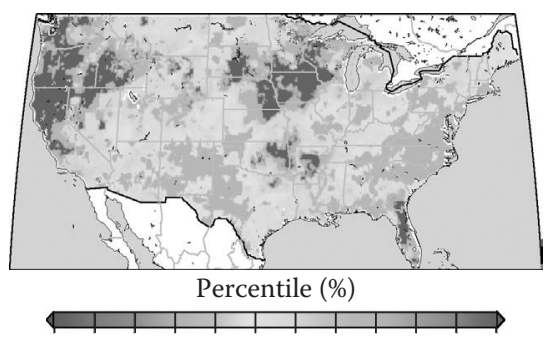

(c) $0 \quad 2 \quad 5 \quad 102030 \quad 70 \quad 80909598100$

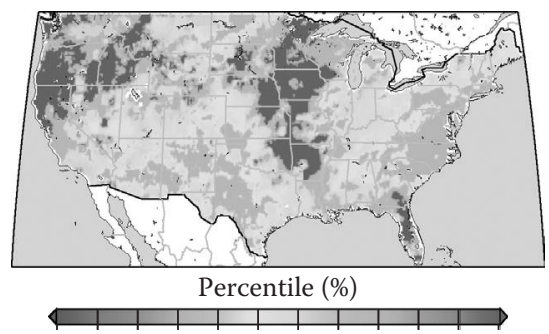

(e) $0 \quad 2 \quad 5 \quad 1020307080909598100$

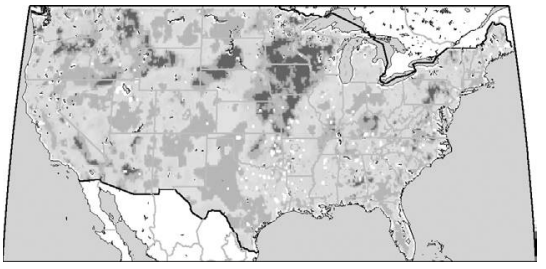

Percentile (\%)
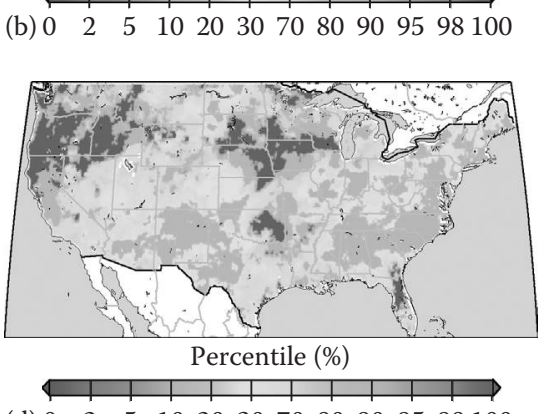

(d) $0 \quad 2 \quad 5 \quad 10 \quad 2030 \quad 70 \quad 8090 \quad 9598100$

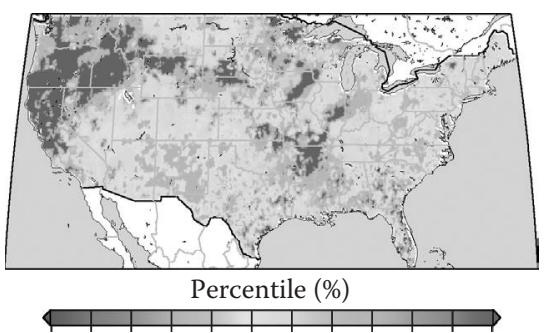

(f) $0 \begin{array}{lllllllllll} & 2 & 5 & 10 & 20 & 30 & 70 & 80 & 90 & 9598100\end{array}$

FIGURE 10.10 (See color insert.) (a) Dynamic range (\% vol.) of AMSR-E daily soil moisture and (b-f) examples of monthly soil moisture percentiles for October 2007 for (b) AMSR-E, (c) Noah, (d) Mosaic, (e) SAC, and (f) VIC.

is derived from a combination of the sensitivity of the AMSR-E sensor, the LSMEM retrieval model, and the climate forcing variability. The rest of Figure 10.10 compares the AMSR-E-based soil moisture data for October 2007 with data from the four NLDAS-2 models taken from their top soil layer output. Since the AMSR-E retrievals and the modeled data could not be compared directly because they represent different soil layer thicknesses, they were normalized through the conversion to monthly percentiles based on the data from 2002 to 2008. To increase the sample size for calculating the percentiles, data from eight neighboring pixels are included, thus trading space for time. In this example, the AMSR-E data show remarkable similarity to the wet and dry regions depicted by the models. The largest differences are in regions of denser vegetation in the east, where the retrievals are expected to be less accurate, and the mountainous areas of the southwest, where terrain will affect the retrievals.

Time series (Figure 10.11) and correlation maps (Figure 10.12) between the retrievals and the models indicate consistency in the southwest United States and 

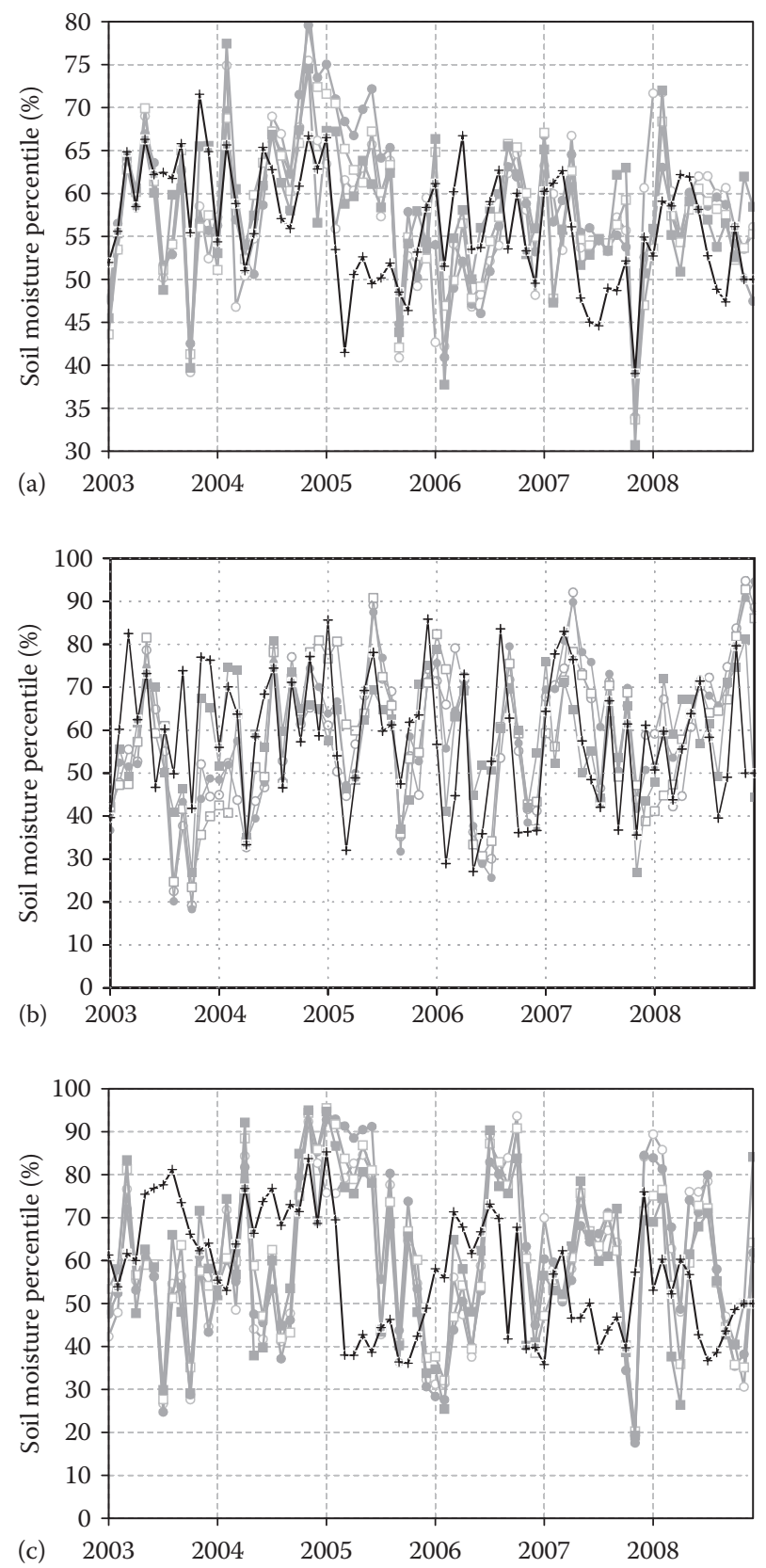

FIGURE 10.11 Time series of monthly soil moisture percentiles from AMSR-E and three NLDAS-2 LSMs (Noah, Mosaic, and SAC) for (a) the conterminous United States, (b) Northern Plains $\left(40^{\circ}-49^{\circ} \mathrm{N}, 95^{\circ}-105^{\circ} \mathrm{W}\right)$, (c) Four Corners region $\left(33^{\circ}-40^{\circ} \mathrm{N}, 105^{\circ}-115^{\circ} \mathrm{W}\right)$, and 


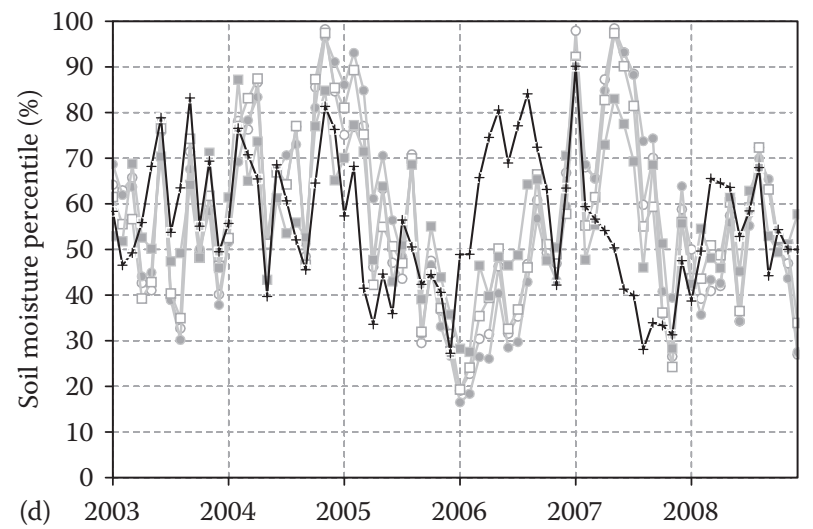

FIGURE 10.11 (continued) (d) Southern Plains/Texas $\left(25^{\circ}-37^{\circ} \mathrm{N}, 95^{\circ}-105^{\circ} \mathrm{W}\right)$.

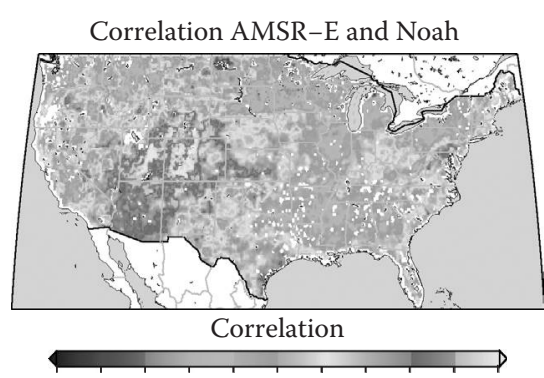

$\begin{array}{lllllll}-0.5-0.4-0.3-0.2-0.1 & 0.0 & 0.1 & 0.2 & 0.3 & 0.4 & 0.5\end{array}$

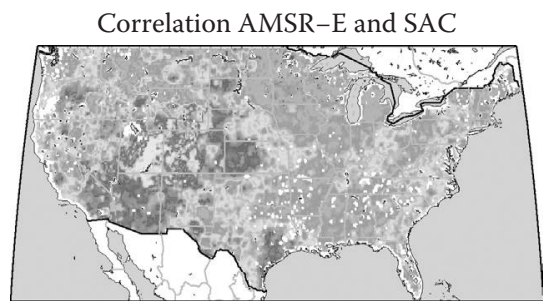

Correlation

\begin{tabular}{lllllllll}
\hline & $0.5-0.4-0.3-0.2-0.1$ & 0.0 & 0.1 & 0.2 & 0.3 & 0.4 & 0.5
\end{tabular}
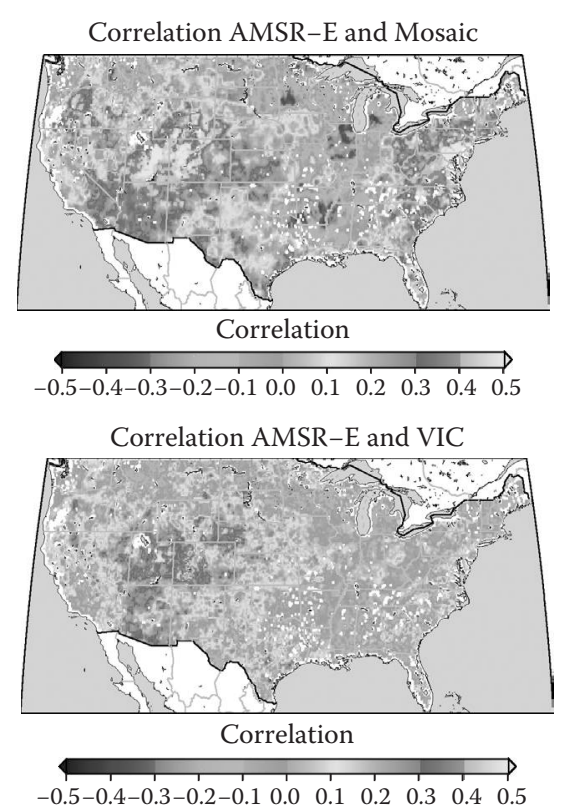

FIGURE 10.12 (See color insert.) Correlation between monthly AMSR-E and LSM monthly soil moisture percentiles for 2002-2008.

central Great Plains in line with the regions of retrievability presented in Figure 10.9. The correlation with Mosaic in the east is particularly strong despite the dense vegetation cover, which may be related to a decreasing trend in the AMSR-E and Mosaic data that may be an artifact of the short time period (2002-2008) of the comparison, rather than any physical connection. The Mosaic model also possesses a faster hydrologic cycle relative to the other models, instilling a more rapid connection between soil moisture and surface evaporation. Figure 10.11 shows reasonable agreement among the time series at regional and even national scales, although 
there are some inconsistencies. For example, there are considerable differences in 2005-2006 for the United States and the four corners regions and in 2006-2007 in the southern Plains-Texas region. For the latter, the differences may be related to the severe drought in 2006 and subsequent flooding conditions in 2007. In periods of extreme dry or wet conditions, the differences in the ASMR-E and model soil moisture estimates might be magnified. For example, the AMSR-E retrievals represent the top $1 \mathrm{~cm}$ of the soil, which will tend to become wet and dry more quickly than the underlying deeper $(10 \mathrm{~cm})$ layer represented by the models. In a wet period, standing water may contaminate the AMSR-E retrievals. Overall, however, there appears to be useful information in the retrieved values that reflects variation in wet and dry spells and may help improve model-based drought monitoring, especially in regions of sparse observational networks.

\subsubsection{Synergy with Other Remote Sensing Signals of Drought}

This book describes several newly developed remotely sensed drought products, many of which can be integrated into the NLDAS-2 either as improved inputs or assimilated signals of surface and subsurface moisture. In general, each of the drought products represents a different aspect of the hydrologic cycle or state of vegetation. In some cases (e.g., soil moisture and total water storage), they represent similar or overlapping quantities but provide complementary information that draws from the strengths of the individual sensor, retrieval algorithm, or characteristics of the retrieval. When combined, these mostly independent products can provide a more holistic view of drought and the hydrologic cycle in general, as well as allowing quantification of dependencies and feedbacks between components such as tracking the propagation of drought through the hydrologic and ecological systems.

A challenge for the scientific and user community is to determine the consistency among these different products and how they may be combined in useful ways to improve drought assessment. A flexible modeling system such as the NLDAS has the potential to provide the framework for merging these various products into a consistent, continuous in space and time, and robust picture of drought, by providing the hooks to tie the individual pieces together. From the perspective of the modeling, this can also be viewed as the use of remote sensing products to correct the errors in the models and their input data. Much work has already been carried out to merge remote sensing products with terrestrial modeling, some of which is discussed in this book (Chapters 7 and 11) in the context of drought. The rest of this section describes the potential to leverage from these activities to merge remote sensing and modeling within the NLDAS.

High-quality and high-resolution precipitation data are crucial for depicting the development and recovery of drought. Better estimates of precipitation in the NLDAS are likely to lead to better representation of land surface hydrology and drought, but this is dependent on the region and application. Over the United States, the density of ground observations of precipitation and other meteorological data is relatively high as compared to locations such as central Africa. However, even in the United States, gauge density is often not optimal for representing the spatial and temporal variability of precipitation and soil moisture. The problem of sparse gauge coverage is somewhat overcome in the NLDAS through the merging of gauge 
data with ground radar data. Nevertheless, radar coverage is not complete spatially and is prone to error for a number of reasons, including bright-band, elevation, and range effects that lead to a complex nonlinear relationship between radar reflectivity and rainfall rate at the surface (Krajewski and Smith, 2002). There is, therefore, potential for utilizing remote sensing-based estimates of precipitation to provide high-resolution complementary information to existing products used as input to the NLDAS (Chapters 12-15). In some regions, this is likely the best and sometimes the only source of precipitation information, and its potential has been demonstrated in several regional applications such as FEWS NET (Verdin et al., 2005) and the Princeton African Drought Monitor (Sheffield et al., 2008c).

In this chapter and Chapter 9, the potential of remotely sensed soil moisture as a drought assessment tool has been presented. There is further opportunity to exploit and extend this capability through assimilation into the NLDAS or similar land surface modeling system to provide a more complete view of drought and correct for model structural and input errors. Assimilation of remotely sensed soil moisture information from passive/active microwave into LSMs has been demonstrated previously (Houser et al., 1998; Crow and Wood, 2003; Reichle and Koster, 2005; Scipal et al., 2008) and can provide improvement in skill for assessment of both droughts and floods (Bolten et al., 2010; Brocca et al., 2010). Complementary information on soil moisture may be obtained from thermal infrared (TIR) remote sensing, which indirectly estimates soil moisture from the thermal response of the vegetation canopy to soil water stress. TIR soil moisture retrievals are described more fully in Chapter 7, which also elucidates their potential for drought monitoring. Microwave (passive and active) and TIR approaches have their strengths and limitations but together provide complementary information. Many of the issues described earlier regarding microwave-based soil moisture can be addressed with TIR approaches (including sampling of the root zone, skill in regions of denser vegetation, and higher spatial resolution) (Hain et al., 2011). Conversely, the limitations of TIR (such as lower temporal sampling due to cloud cover) can be partly addressed by the microwave approach. TIR retrievals have been demonstrated as useful for assimilation into LSMs (e.g., Crow et al., 2008). Further, the complementary information in both TIR and microwave retrievals has the potential to be mined in a joint data assimilation framework to provide improved estimates of soil moisture relative to assimilation of either in isolation (Hain, 2010; Li et al., 2010). Remotely sensed soil moisture can also provide complementary information to remotely sensed precipitation retrievals. For example, these retrievals represent the on-the-ground signature of actual rainfall as compared to remote sensing estimates that represent aboveground precipitation rates that are subject to advection before reaching the ground (McCabe et al., 2008).

The NLDAS LSMs do not explicitly model groundwater, although their parameterizations of baseflow represent the contribution of deeper soil layers to streamflow. The models are therefore subject to biases in their depiction of drought dynamics and especially in the potentially mediating effect of groundwater on drought propagation. Chapter 11 demonstrates how GRACE measurements of total water storage change (groundwater, soil moisture, surface water, snow, lakes, streams, and wetlands) provide useful information on total water storage dynamics and particularly groundwater. Chapter 11 also demonstrates how GRACE data, despite their coarse 
resolution, could be ingested into an LSM that possesses a groundwater component to help improve the depiction of longer-scale dynamics and may be crucial for improving drought assessment in groundwater-dominated regions. Similar to soil moisture retrievals, the blending of coarse-resolution GRACE data with higherresolution modeling bridges the gap between observational sampling issues and the need for continuous and consistent drought information.

Further avenues for merging remote sensing information into the NLDAS to provide a consistent and more robust view of drought exist, such as with snow and vegetation products. For snow, this is particularly important in snow-dominated regions such as the western United States where water resources and agriculture are highly dependent on winter snow accumulation and timing of spring melt. Where local information on snowfall and accumulation is limited to gauges in valley bottoms or, at best, sparse highelevation networks, remote sensing is an underexploited resource that can address some of these issues, as shown in Chapter 15. For vegetation, the current NLDAS models use a seasonal representation of vegetation phenology (in terms of LAI and other parameters) that is fixed from year to year. As well as being inconsistent with remote sensingbased estimates of vegetation stress, this also has implications for the simulation of soil moisture and hydrological drought in the models because of the vegetation controls on interception and transpiration. A simple approach to improving this is to incorporate remotely sensed vegetation information, such as NDVI, into the model inputs.

\subsection{SUMMARY}

The NLDAS-2 provides a temporally and spatially consistent, quantitative depiction of drought history, current conditions, and future seasonal changes. The use of observation-forced, physically based models enables all aspects of hydrological drought to be assessed and multiple models allow for the estimation of uncertainties. Comparison across models shows encouraging consistency in the depiction of largescale drought events, although the development of drought at more localized scales appears to differ considerably across models despite the commonality of meteorological forcings and underlying landscape parameters. Improvements can be made, particularly through the increased use of remote sensing data. For example, remotely sensed soil moisture has the potential to augment the system, either directly as an additional monitoring variable or indirectly via assimilation. Despite the coarse spatial resolution and limited utility over areas with high vegetation biomass density, microwave-based remote sensing of soil moisture is responsive to precipitation and can discern between wet or dry periods at monthly to seasonal time scales, which is useful for drought monitoring. Microwave soil moisture retrievals may actually provide a better indication of wet areas than radar or in regions with sparse gauge networks, and can be used to augment NLDAS-based model estimates using an assimilation framework to merge the NLDAS and remote sensing soil moisture products. There is also potential to expand the system globally, particularly for regions such as Africa with sparse ground observations (Sheffield et al., 2008c), where there is heavy reliance on remote sensing to provide meteorological data for the forcings and hydrologic variables used for validation and assimilation. From a broader perspective, an assimilation approach within an NLDAS-type system is likely the most 
promising way forward for exploiting the breadth of complementary remote sensing products described in this book and providing a more consistent picture of drought.

\section{ACKNOWLEDGMENTS}

The authors acknowledge the support of the NOAA/OGP/CPPA, NOAA grant NA08OAR4310579, and the NLDAS team: Mike Ek, Youlong Xia, and Ken Mitchell (NCEP/EMC); Eric F. Wood and Justin Sheffield (Princeton University); Lifeng Luo (Michigan State University); Brian C. Cosgrove (NWS/OHD); D. Mocko and C. Alonge (NASA/Goddard Space Flight Center; GSFC); Dennis P. Lettenmaier and Ben Livneh (University of Washington); Pedro Restrepo, John Schaake, and Victor Koren (NWS/OHD); Kingste Mo and Huug Van den Dool (NWS/CPC); and Yun Fan (NWS/Office of Science and Technology; OST).

\section{REFERENCES}

Andreadis, K.M., E.A. Clark, A.W. Wood, A.F. Hamlet, and D.P. Lettenmaier. 2005. Twentiethcentury drought in the conterminous United States. Journal of Hydrometeorology 6:985-1001.

Betancourt, J. 2003. The current drought (1999-2003) in historical perspective. Southwest Drought Summit, Northern Arizona University, Flagstaff, May 12-13. http://www.mpcer.nau.edu/megadrought/Betancourt\%2520Abstract.pdf (accessed on May 2010).

Betts, A., F. Chen, K. Mitchell, and Z. Janjic. 1997. Assessment of the land surface and boundary layer models in two operational versions of the NCEP Eta model using FIFE data. Monthly Weather Review 125:2896-2916.

Bolten, J.D., W.T. Crow, X. Zhan, T.J. Jackson, and C.A. Reynolds. 2010. Evaluating the utility of remotely sensed soil moisture retrievals for operational agricultural drought monitoring. IEEE Journal of Selected Topics in Applied Earth Observations and Remote Sensing 3(1):57.

Brocca, L., F. Melone, T. Moramarco, W. Wagner, V. Naeimi, Z. Bartalis, and S. Hasenauer. 2010. Improving runoff prediction through the assimilation of the ASCAT soil moisture product. Hydrology and Earth System Science 14:1881-1893.

Burnash, R.J.C., R.L. Ferral, and R.A. McGuire. 1973. A Generalized Stream Flow Simulation System: Conceptual Models for Digital Computers. Joint Federal State River Forecast Center, Sacramento, California.

Chen, F., Z. Janjic, and K. Mitchell. 1997. Impact of atmospheric surface-layer parameterizations in the new land-surface scheme of the NCEP mesoscale Eta model. BoundaryLayer Meteorology 85:391-421.

Cosgrove, B.A., D. Lohmann, K.E. Mitchell, P.R. Houser, E.F. Wood, J.C. Schaake, A. Robock, C. Marshall, J. Sheffield, Q. Duan, L. Luo, R.W. Higgins, R.T. Pinker, J.D. Tarpley, and J. Meng. 2003. Real-time and retrospective forcing in the North American Land Data Assimilation System (NLDAS) project. Journal of Geophysical Research 108(D22):8842, doi:10.1029/2002JD003118.

Crow, W.T. and E.F. Wood. 2003. The assimilation of remotely sensed soil brightness temperature imagery into a land surface model using ensemble Kalman filtering: A case study based on ESTAR measurements during SGP97. Advances in Water Resources 26:137-149.

Crow, W.T., W.P. Kustas, and J.H. Prueger. 2008. Monitoring root-zone soil moisture through the assimilation of a thermal remote sensing-based soil moisture proxy into a water balance model. Remote Sensing of Environment 112(4):1268-1281. 
Daly, C., R.P. Neilson, and D.L. Phillips. 1994. A statistical-topographic model for mapping climatological precipitation over mountainous terrain. Journal of Applied Meteorology 33:140-158.

Das, N., D. Entekhabi, and E. Njoku. 2011. An algorithm for merging SMAP radiometer and radar data for high resolution soil moisture retrieval. IEEE Transactions on Geoscience and Remote Sensing 49(5):1504-1512.

Day, G.N. 1985. Extended streamflow forecasting using NWSRFS. Journal of Water Resources Planning and Management 111:157-170.

Drusch, M., E.F. Wood, H. Gao, and A. Thiele. 2004. Soil moisture retrieval during the southern great plains hydrology experiment 1999: A comparison between experimental remote sensing data and operational products. Water Resources Research 40(2):21. doi:10.1029/2003WR002441.

Ek, M.B., K.E. Mitchell, Y. Lin, E. Rodgers, P. Grunman, V. Koren, G. Gayno, and J.D. Tarpley. 2003. Implementation of Noah land surface model advances in the National Centers for Environmental Prediction operational mesoscale Eta model. Journal of Geophysical Research 108:8851, doi:10.1029/2002JD003296.

Entekhabi, D., T.J. Jackson, E. Njoku, P. O’Neill, and J. Entin. 2008. Soil moisture active/passive (SMAP) mission concept. Proceedings of SPIE 7085:70850H, doi:10.1117/12.795910.

Gutman, G. and A. Ignatov. 1998. The derivation of the green vegetation fraction from NOAA/ AVHRR data for use in numerical weather prediction models. International Journal of Remote Sensing 19:1533-1543.

Hain, C.R. 2010. Developing a dual assimilation approach for thermal infrared and passive microwave soil moisture retrievals. PhD. dissertation, Department of Atmospheric Science, University of Alabama.

Hain, C.R., W.T. Crow, J.R. Mecikalski, M.C. Anderson, and T. Holmes. 2011. An intercomparison of available soil moisture estimates from thermal-infrared and passive microwave remote sensing and land-surface modeling. Journal of Geophysical ResearchAtmospheres (in press).

Hansen, M.C., R.S. DeFries, J.R.G. Townshend, and R. Sohlberg. 2000. Global land cover classification at $1 \mathrm{~km}$ spatial resolution using a classification tree approach. International Journal of Remote Sensing 21:1331-1364.

Houser, P.R., W.J. Shuttleworth, J.S. Famiglietti, H.V. Gupta, K.H. Syed, and D.C. Goodrich. 1998. Integration of soil moisture remote sensing and hydrologic modeling using data assimilation. Water Resources Research 34:3405-3420.

Joyce, R.J., J.E. Janowiak, P.A. Arkin, and P. Xie. 2004. CMORPH: A method that produces global precipitation estimates from passive microwave and infrared data at high spatial and temporal resolution. Journal of Hydrometeorology 5:487-503.

Kerr, Y.H. 2007. Soil moisture from space: Where are we? Hydrogeology Journal 15:117-120.

Koster, R. and M. Suarez. 1994. The components of the SVAT scheme and their effects on a GCM's hydrological cycle. Advances in Water Resources 17:61-78.

Koster, R. and M. Suarez. 1996. Energy and water balance calculations in the Mosaic LSM. NASA Technical Memo 104606 9:76.

Krajewski, W.F. and J.A. Smith. 2002. Radar hydrology: Rainfall estimation. Advances in Water Resources 25(8-12):1387-1394.

Kumar, S.V., C.D. Peters-Lidard, Y. Tian, J. Geiger, P.R. Houser, S. Olden, L. Lighty, J.L. Eastman, P. Dirmeyer, B. Doty, J. Adams, E. Wood and J. Sheffield. 2006. LIS-An interoperable framework for high resolution land surface modeling. Environmental Modeling and Software 21:1402-1415.

Lawford, R.G. 1992. Research implications of the 1988 Canadian Prairie Provinces drought. Natural Hazards 6:109-129. 
Lawrimore, J., R.R. Heim, M. Svoboda, V. Swail, and P.J. Englehart. 2002. Beginning a new era of drought monitoring across North America. Bulletin of the American Meteorological Society 83:1191-1192.

Lawrimore, J. and S. Stephens. 2003. Climate of 2002 Annual Review. NOAA National Climatic Data Center, Asheville, North Carolina. http://lwf.ncdc.noaa.gov/oa/climate/research/2002/ann/drought-summary.html (accessed on June 2010).

Li, F., W.T. Crow, and W.P. Kustas. 2010. Towards the estimation of root-zone soil moisture via the simultaneous assimilation of thermal and microwave soil moisture retrievals. Advances in Water Resources 33(2):201-214.

Li, H., L. Luo, E.F. Wood, and J. Schaake. 2009. The role of initial conditions and forcing uncertainties in seasonal hydrologic forecasting. Journal of Geophysical Research 114:D04114, doi:10.1029/2008JD010969.

Liang, X., D.P. Lettenmaier, E.F. Wood, and S.J. Burges. 1994. A simple hydrologically based model of land surface water and energy fluxes for GCMs. Journal of Geophysical Research 99:14415-14428.

Liu, Y.Y., R.M. Parinussa, W.A. Dorigo, R.A.M. De Jeu, W. Wagner, A.I.J.M. van Dijk, M.F. McCabe, and J.P. Evans. 2011. Developing an improved soil moisture dataset by blending passive and active microwave satellite-based retrievals. Hydrology and Earth System Sciences 15:425-436.

Lohmann, D., K.E. Mitchell, P.R. Houser, E.F. Wood, J.C. Schaake, A. Robock, B.A. Cosgrove, J. Sheffield, Q. Duan, L. Luo, R.W. Higgins, R.T. Pinker, and J.D. Tarpley. 2004. Streamflow and water balance intercomparison of four land surface models in the North American Land Data Assimilation System (NLDAS). Journal of Geophysical Research 109:D07S91, doi:10.1029/2003JD003517.

Luo, L., A. Robock, K.E. Mitchell, P.R. Houser, E.F. Wood, J.C. Schaake, D. Lohmann, B. Cosgrove, F. Wen, J. Sheffield, Q. Duan, R.W. Higgins, R.T. Pinker, and J.D. Tarpley. 2003. Validation of the North American Land Data Assimilation System (NLDAS) retrospective forcing over the Southern Great Plains. Journal of Geophysical Research 108(D22):8843, doi:10.1029/2002JD003246.

Luo, L. and E.F. Wood. 2007. Monitoring and predicting the 2007 U.S. drought. Geophysical Research Letters 34:L22702, doi:10.1029/2007GL031673.

Luo, L. and E.F. Wood. 2008. Use of Bayesian merging techniques in a multi-model seasonal hydrologic ensemble prediction system for the Eastern U.S. Journal of Hydrometeorology 5:866-884.

McCabe, M.F., E.F. Wood, R. Wojcik, M. Pan, J. Sheffield, H. Gao, and H. Su. 2008. Hydrological consistency using multi-sensor remote sensing data for water and energy cycle studies. Remote Sensing of Environment 112(2):430-444.

Mesinger, F., G. DiMego, E. Kalnay, K. Mitchell, P. Shafran, W. Ebisuzaki, D. Jovic, J. Woollen, E. Rogers, E. Berbery, M. Ek, Y. Fan, R. Grumbine, W. Higgins, H. Li, Y. Lin, G. Manikin, D. Parrish, and W. Shi. 2006. North American regional reanalysis. Bulletin of the American Meteorological Society 87(3):343-360.

Mitchell, K.E., D. Lohmann, P.R. Houser, E.F. Wood, J.C. Schaake, A. Robock, B.A. Cosgrove, J. Sheffield, Q. Duan, L. Luo, R.W. Higgins, R.T. Pinker, J.D. Tarpley, D.P. Lettenmaier, C.H. Marshall, J.K. Entin, M. Pan, W. Shi, V. Koren, J. Meng, B.H. Ramsey, and A.A. Bailey. 2004. The multi-institution North American Land Data Assimilation System (NLDAS): Utilizing multiple GCIP products and partners in a continental distributed hydrological modeling system. Journal of Geophysical Research 109:D07S90, doi:10.1029/2003JD003832.

Myneni, R.B., R.R. Nemani, and S.W. Running. 1997. Estimation of global leaf area index and absorbed PAR using radiative transfer models. IEEE Transactions on Geoscience and Remote Sensing 35:1380-1393. 
Narayan, U., V. Lakshmi, and E.G. Njoku. 2004. Retrieval of soil moisture from passive and active L/S band sensor during the soil moisture experiment in 2002 (SMEX02). Remote Sensing of the Environment 92(4):483-496.

NCDC (National Climate Data Center). 2009. Billion dollar climate and weather disasters, 1980-2009. NOAA National Climatic Data Center, Asheville, North Carolina. http://www.ncdc.noaa.gov/img/reports/billion/state2009.pdf (accessed on May 2010).

Njoku, E.G., T.J. Jackson, V. Lakshmi, T.K. Chan, and S.V. Nghiem. 2003. Soil moisture retrieval from AMSR-E. IEEE Transactions on Geoscience Remote Sensing 41(2):215-228.

Owe, M., R.A.M. de Jeu, and T.H.R. Holmes. 2008. Multi-sensor historical climatology of satellite derived global land surface soil moisture. Journal of Geophysical Research 113:F01002, doi:10.1029/2007JF000769.

Pan, M., J. Sheffield, E.F. Wood, K.E. Mitchell, P.R. Houser, J.C. Schaake, A. Robock, D. Lohmann, B. Cosgrove, Q. Duan, L. Luo, R.W. Higgins, R.T. Pinker, and J.D. Tarpley. 2003. Snow process modeling in the North American Land Data Assimilation System (NLDAS): 2. Evaluation of model simulated snow water equivalent. Journal of Geophysical Research 108(D22):8850, doi:10.1029/2003JD003994.

Pinker, R.T., J.D. Tarpley, I. Laszlo, K.E. Mitchell, P.R. Houser, E.F. Wood, J.C. Schaake, A. Robock, D. Lohmann, B.A. Cosgrove, J. Sheffield, Q. Duan, L. Luo, and R.W. Higgins. 2003. Surface radiation budgets in support of the GEWEX Continental-Scale International Project (GCIP) and the GEWEX Americas Prediction Project (GAPP), including the North American Land Data Assimilation System (NLDAS) project. Journal of Geophysical Research 108(D22):8844, doi:10.1029/2002JD003301.

Reichle, R.H. and R.D. Koster. 2005. Global assimilation of satellite surface soil moisture retrievals into the NASA Catchment land surface model. Geophysical Research Letters 32:L02404, doi:10.1029/2004GL021700.

Riebsame, W.E., S.A. Changnon, and T.R. Karl. 1991. Drought and Natural Resources Management in the United States: Impacts and Implications of the 1987-89 Drought. Boulder, Colorado: Westview Press.

Robock, A., L. Luo, E.F. Wood, F. Wen, K.E. Mitchell, P.R. Houser, J.C. Schaake, D. Lohmann, B. Cosgrove, J. Sheffield, Q. Duan, R.W. Higgins, R.T. Pinker, J.D. Tarpley, J.B. Basara, and K.C. Crawford. 2003. Evaluation of the North American Land Data Assimilation System over the Southern Great Plains during the warm season. Journal of Geophysical Research 108(D22):8846, doi:10.1029/2002JD003245.

Rodell, M., P.R. Houser, U. Jambor, J. Gottschalck, K. Mitchell, C.-J. Meng, K. Arsenault, B. Cosgrove, J. Radakovich, M. Bosilovich, J.K. Entin, J.P. Walker, D. Lohmann, and D. Toll. 2004. The global land data assimilation system. Bulletin of the American Meteorological Society 85:381-394.

Saha, S., S. Nadiga, C. Thiaw, J. Wang, W. Wang, Q. Zhang, H.M. van den Dool, H.-L. Pan, S. Moorthi, D. Behringer, D. Stokes, M. Pena, S. Lord, G. White, W. Ebisuzaki, P. Peng, and P. Xie. 2006. The NCEP climate forecast system. Journal of Climate 19:3483-3517.

Schaake, J.C., Q. Duan, V. Koren, K.E. Mitchell, P.R. Houser, E.F. Wood, A. Robock, D.P. Lettenmaier, D. Lohmann, B. Cosgrove, J. Sheffield, L. Luo, R.W. Higgins, R.T. Tinker, and J.D. Tarpley. 2004. An intercomparison of soil moisture fields in the North American Land Data Assimilation System (NLDAS). Journal of Geophysical Research 109:D01S90, doi:10.1029/2002JD003309.

Scipal, K., M. Drusch, and W. Wagner. 2008. Assimilation of a ERS scatterometer derived soil moisture index in the ECMWF numerical weather prediction system. Advances in Water Resources 31:1101-1112.

Sheffield, J., K.M. Andreadis, E.F. Wood, and D.P. Lettenmaier. 2009a. Global and continental drought in the second half of the 20th century: Severity-area-duration analysis and temporal variability of large-scale events. Journal of Climate 22(8):1962-1981. 
Sheffield, J., C.R. Ferguson, T.J. Troy, E.F. Wood, and M.F. McCabe. 2009b. Closing the terrestrial water budget from satellite remote sensing. Geophysical Research Letters 36:L07403, doi:10.1029/2009GL037338.

Sheffield, J., G. Goteti, F. Wen, and E.F. Wood. 2004. A simulated soil moisture based drought analysis for the United States. Journal of Geophysical Research 109:D24108, doi:10.1029/2004JD005182.

Sheffield, J., M. Pan, E.F. Wood, K.E. Mitchell, P.R. Houser, J.C. Schaake, A. Robock, D. Lohmann, B. Cosgrove, Q. Duan, L. Luo, R.W. Higgins, R.T. Pinker, J.D. Tarpley, and B.H. Ramsey. 2003. Snow process modeling in the North American Land Data Assimilation System (NLDAS): 1. Evaluation of model-simulated snow cover extent. Journal of Geophysical Research 108(D22):8849, doi:10.1029/2002JD003274.

Sheffield, J. and E.F. Wood. 2007. Characteristics of global and regional drought, 1950-2000: Analysis of soil moisture data from off-line simulation of the terrestrial hydrologic cycle. Journal of Geophysical Research 112(D17115): 12. doi:10.1029/2006JD008288.

Sheffield, J. and E.F. Wood. 2008a. Global trends and variability in soil moisture and drought characteristics, 1950-2000, from observation-driven simulations of the terrestrial hydrologic cycle. Journal of Climate 21:432-458.

Sheffield J. and E.F. Wood. 2008b. Projected changes in drought occurrence under future global warming from multi-model, multi-scenario, IPCC AR4 simulations. Climate Dynamics 13(1):79-105.

Sheffield, J., E.F. Wood, D.P. Lettenmaier, and A. Lipponen. 2008c. Experimental drought monitoring for Africa. GEWEX News 18(3):4-6.

Svoboda, M., D. LeComte, M. Hayes, R. Heim, K. Gleason, J. Angel, B. Rippey, R. Tinker, M. Palecki, D. Stooksbury, D. Miskus, and S. Stephens. 2002. The drought monitor. Bulletin of the American Meteorological Society 83:1181-1190.

Tang, Q., H. Gao, H. Lu and D.P. Lettenmaier. 2009. Remote sensing: Hydrology. Progress in Physical Geography 33(4):490-509.

Trenberth, K.E. and G.W. Branstator. 1992. Issues in establishing causes of the 1988 drought over North America. Journal of Climate 5:159-172.

Verdin, J., C. Funk, G. Senay, and R. Choularton. 2005. Climate science and famine early warning. Philosophical Transactions of the Royal Society B 360:2155-2168.

Wang A., T.J. Bohn, S.P. Mahanama, R.D. Koster, and D.P. Lettenmaier. 2009. Multimodel ensemble reconstruction of drought over the continental United States. Journal of Climate 22:2694-2712.

Wang, A., D.P. Lettenmaier, and J. Sheffield. 2010. Soil moisture drought in China, 1950-2006. Journal of Climate (in press).

Wilhite, D.A. 2000. Drought as a natural hazard: Concepts and definitions. In Drought: A Global Assessment, ed. D.A. Wilhite, pp. 3-18. London, U.K.: Routledge Publishers.

Wood, A.W. and D.P. Lettenmaier. 2006. A testbed for new seasonal hydrologic forecasting approaches in the western U.S. Bulletin of the American Meteorological Society 87(12):1699-1712.

Wood, E.F., D.P. Lettenmaier, X. Liang, B. Nijssen, and S.W. Wetzel. 1997. Hydrological modeling of continental-scale basins. Annual Review of Earth and Planetary Sciences 25:279-300.

Xia, Y., K. Mitchell, M. Ek, J. Sheffield, E. Wood, L. Luo, B. Cosgrove, C. Alonge, H. Wei, J. Meng, B. Levenieh, D. Lettenmaier, V. Koren, Y. Duan, K. Mo, and Y. Fan. 2012. Continental-scale water and energy flux analysis and validation for the North-American Land Data Assimilation System Project Phase 2 (NLDAS-2), Part 1: Comparison analysis and application of model products. Journal of Geophysical Research (in review).

Yevjevich, V. 1972. Stochastic Processes in Hydrology. Fort Collins, Colorado: Water Resources Publications. 

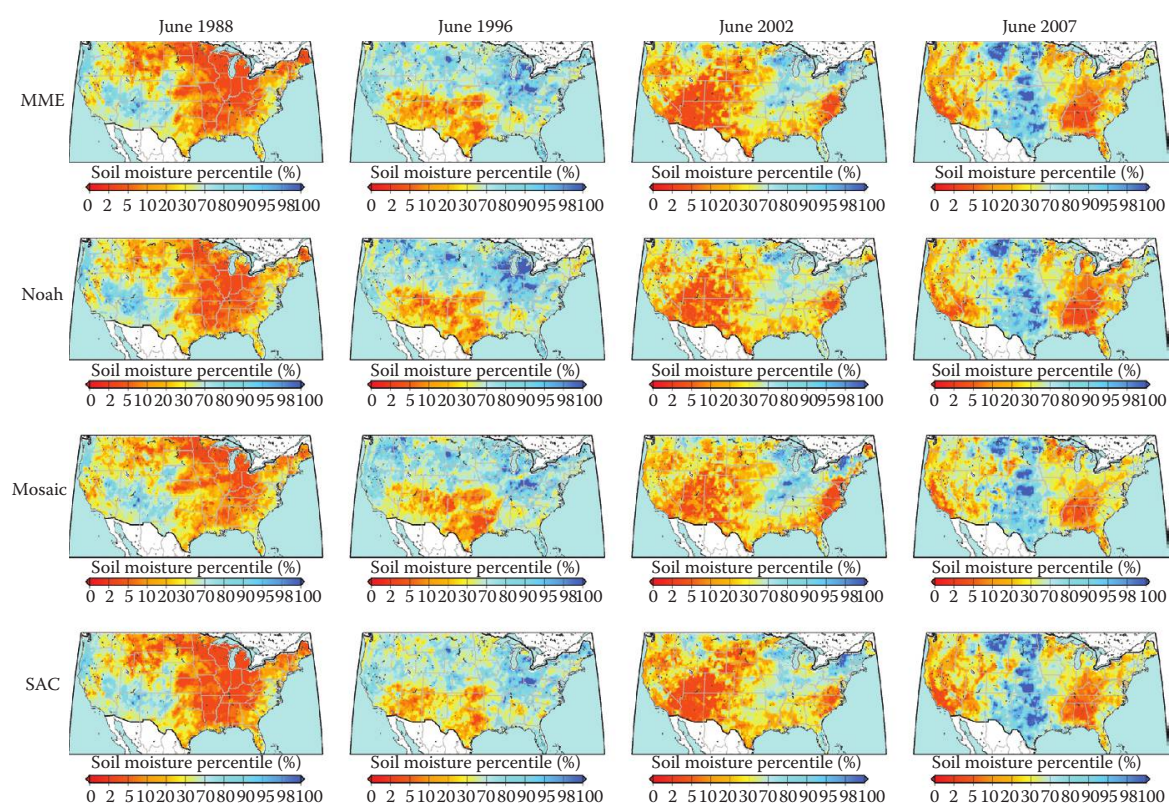

VIC
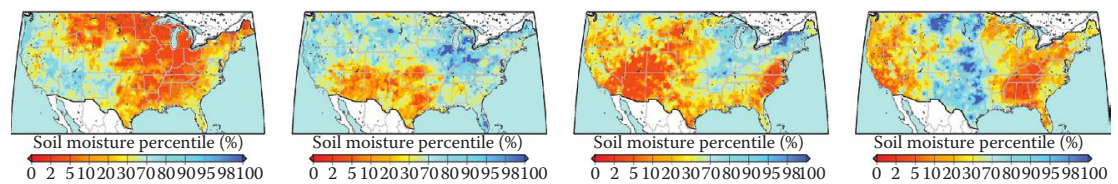

FIGURE 10.4 Snapshots of four major drought events from June soil moisture percentiles from the MME and the four models. Columns are (1) 1988, (2) 1996, (3) 2002, and (4) 2007. 


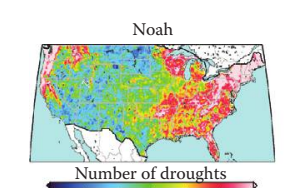

(a) $\begin{array}{lllllll}0 & 5 & 10 & 15 & 20 & 25 & 30\end{array}$

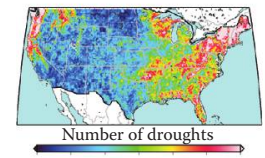

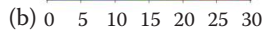

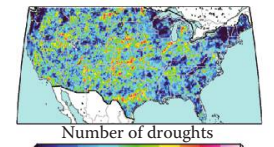

(c) $\begin{array}{llllll}0 & 1 & 2 & 3 & 4 & 5\end{array}$

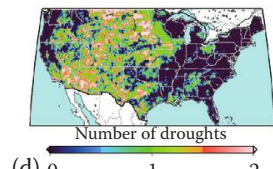

(d) 0

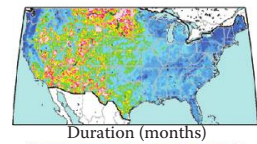

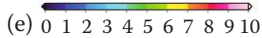
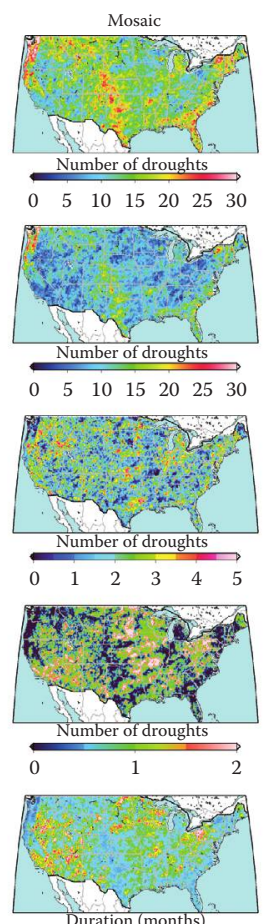

$\longrightarrow$
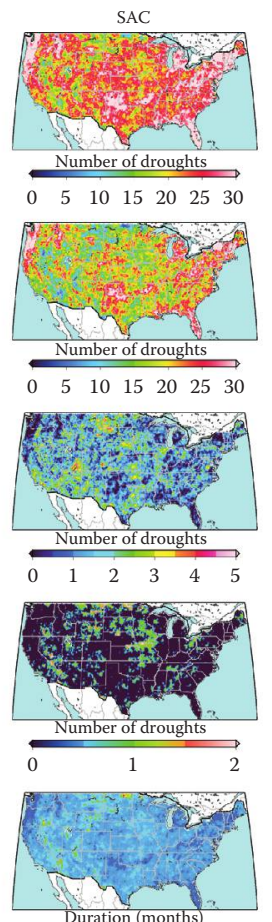

012345678910
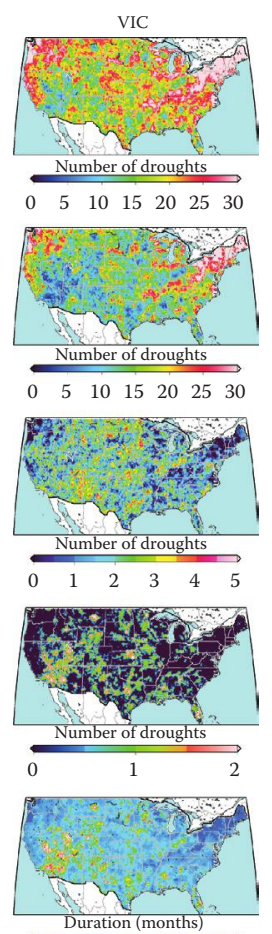

$0 \longdiv { 2 3 4 5 6 7 8 9 1 0 }$

FIGURE 10.5 Statistics of drought duration and frequency for the four LSMs for 1979-2008 calculated from monthly soil moisture percentiles. A drought is defined at each grid cell when the soil moisture percentile drops below $20 \%$. (a) Total number of droughts, (b) number of short-term (1-3 month duration) droughts, (c) number of medium-term (7-12 month duration) droughts, (d) number of long-term (>12 month duration) droughts, and (e) the mean drought duration.

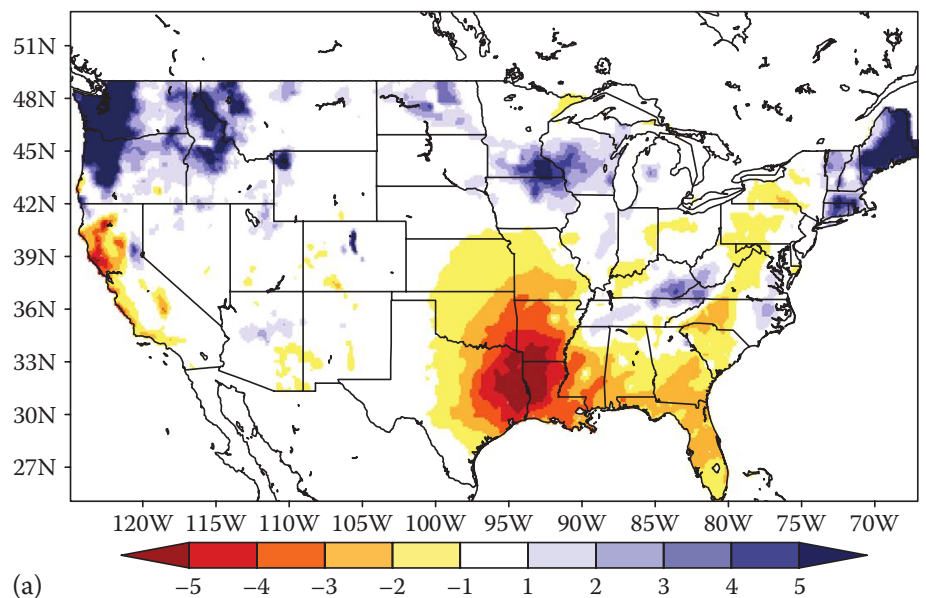

FIGURE 10.6 Example of output fields from the NLDAS-2 drought monitor (http://www.emc.ncep.noaa.gov/mmb/nldas/drought/), showing anomaly data for the week ending on December 16, 2010, for (a) precipitation and multi-model averages of (b) evapotranspiration, (c) runoff, (d) streamflow, (e) soil moisture, and (f) snow water equivalent. 


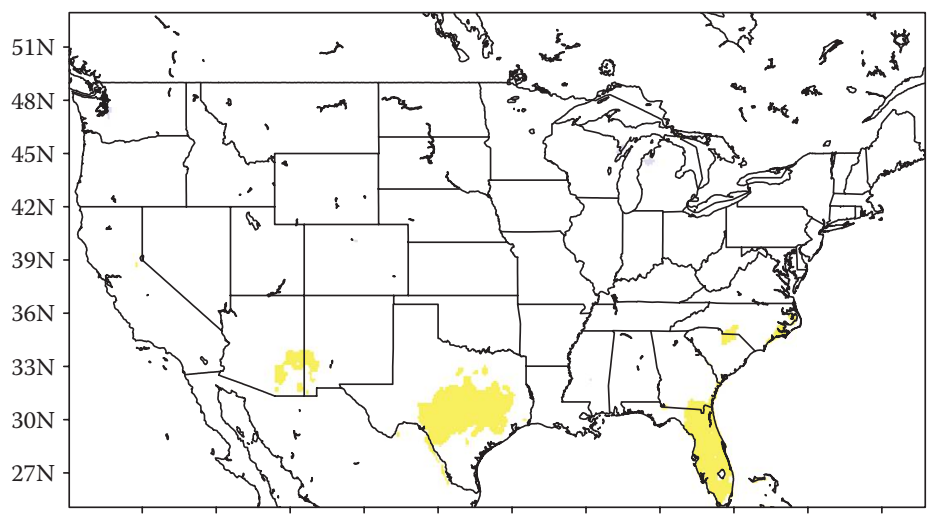

120W 115W 110W 105W 100W 95W 90W $85 \mathrm{~W} \quad 80 \mathrm{~W} \quad 75 \mathrm{~W} \quad 70 \mathrm{~W}$

(b)

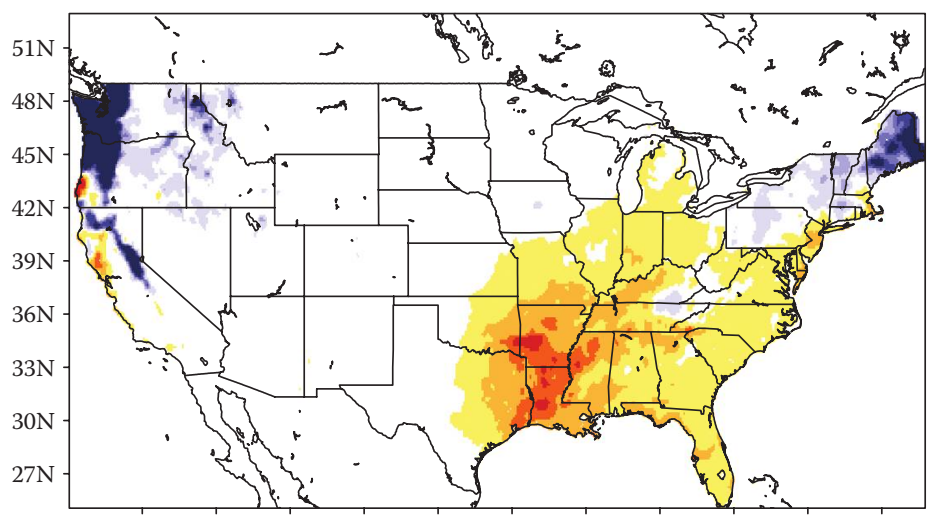

120W 115W 110W 105W 100W 95W 90W 85W $80 \mathrm{~W}$ 75W $70 \mathrm{~W}$

(c)
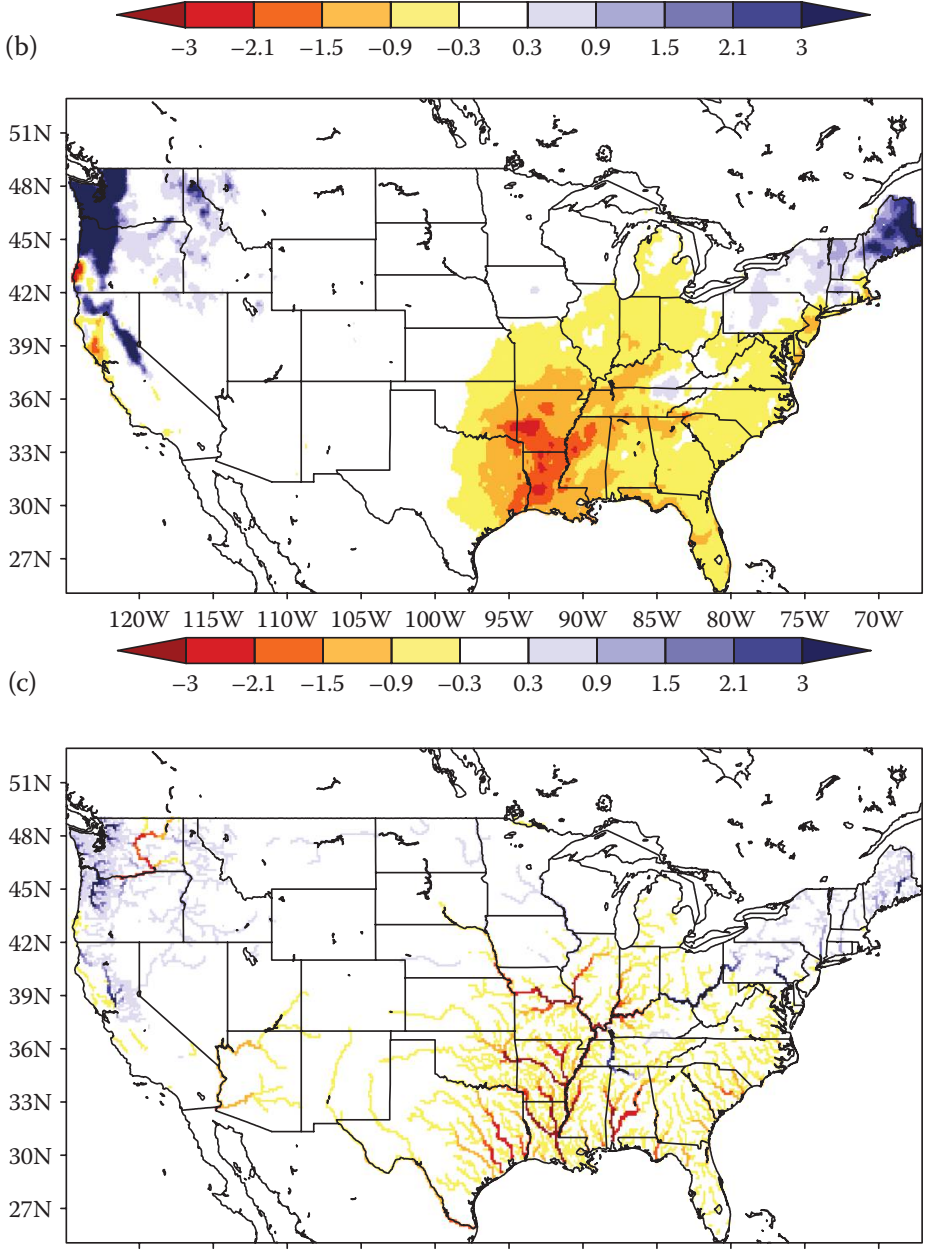

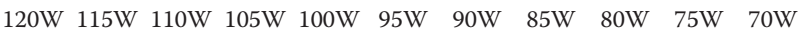

(d)

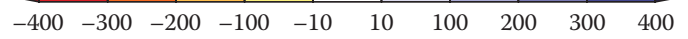

FIGURE 10.6 (continued) 

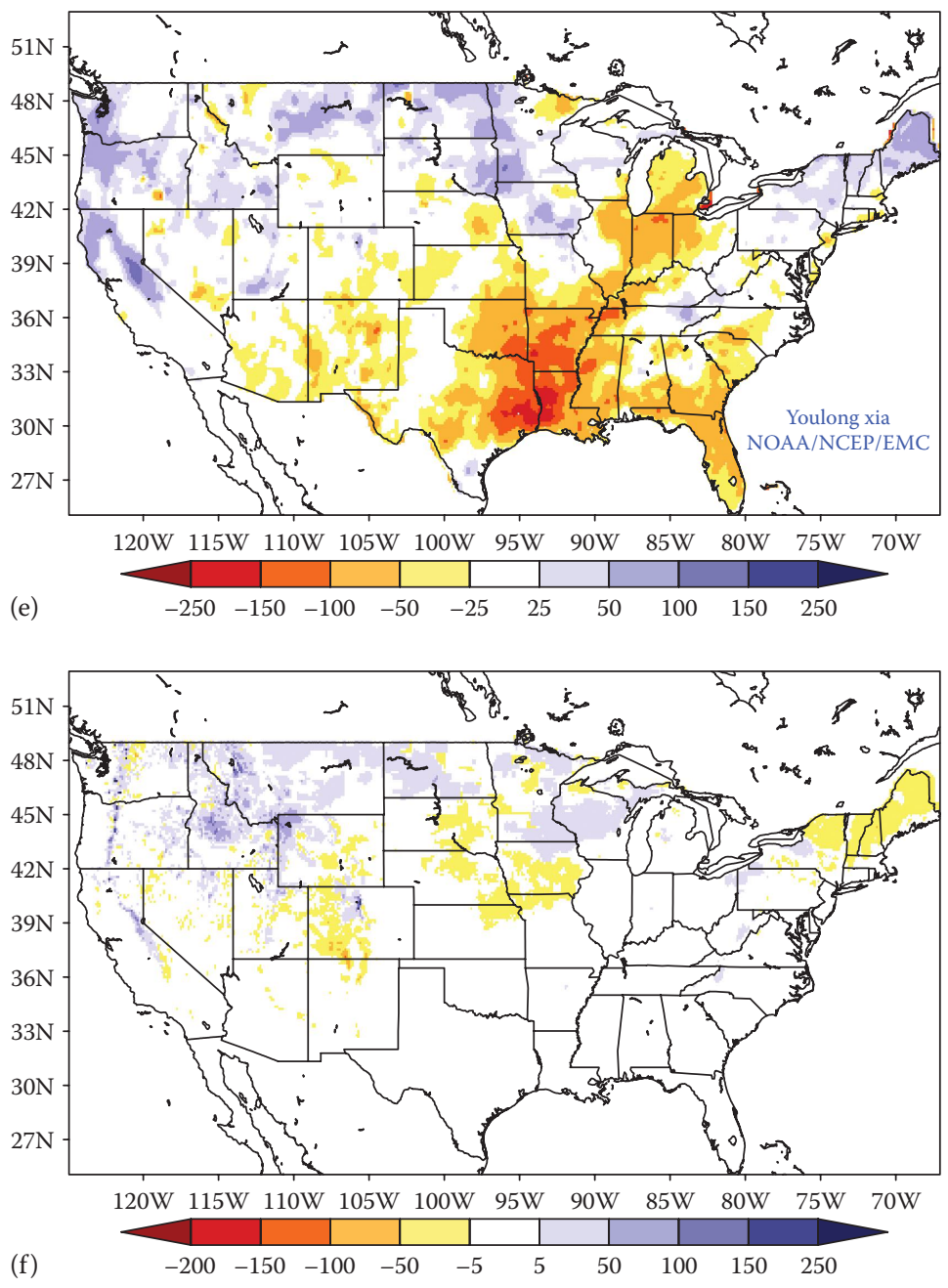

FIGURE 10.6 (continued) 


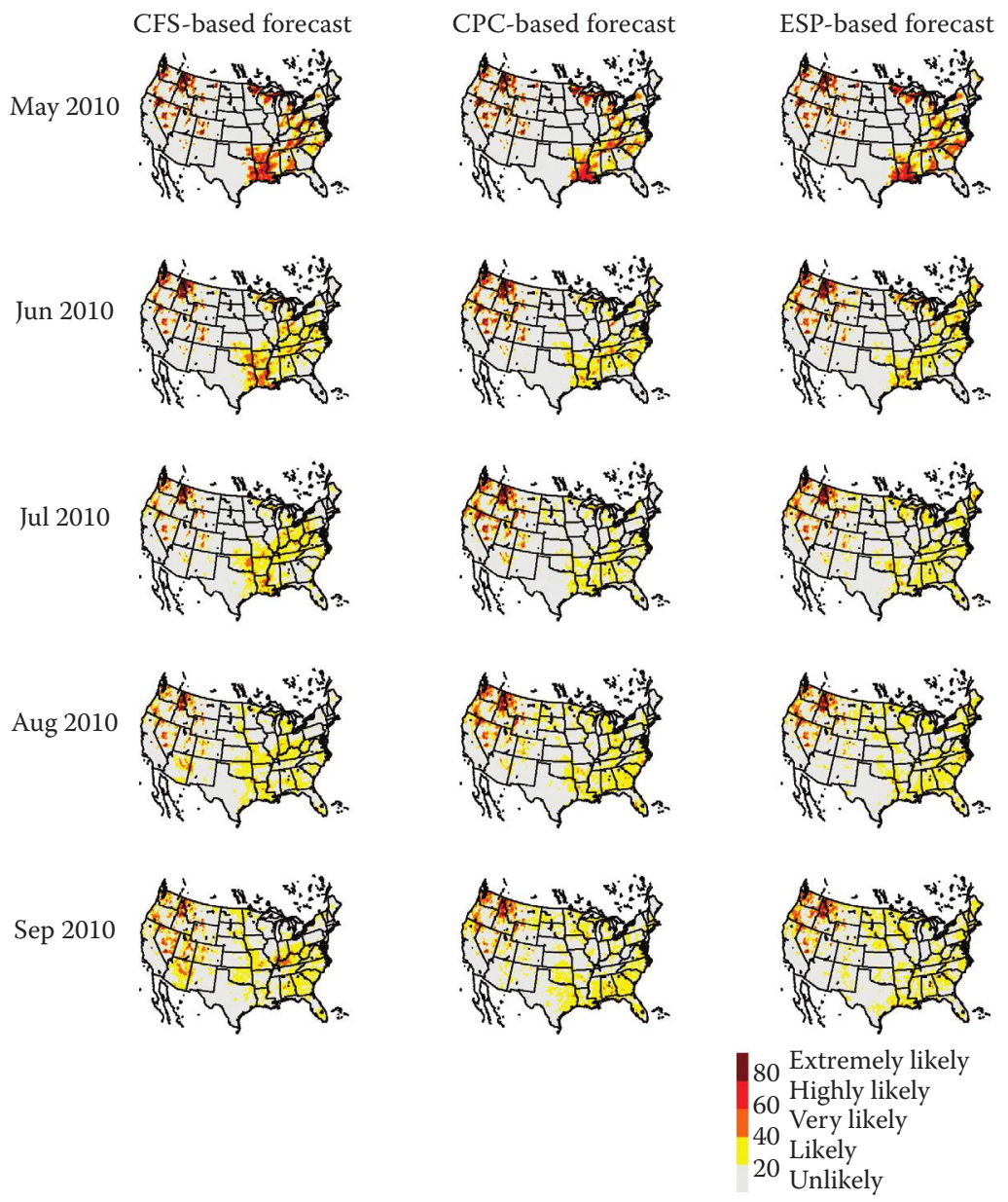

FIGURE 10.7 Example of seasonal forecasts for May through September 2010, showing the likelihood of drought developing or persisting at lead times of 1-6 months. A drought is defined as soil moisture deficits below the 20th percentile, and the likelihood is based on ensemble forecast distributions. Forecasts are based on three methods: (1) CFS, (2) CPC official outlooks, and (3) ESP. 

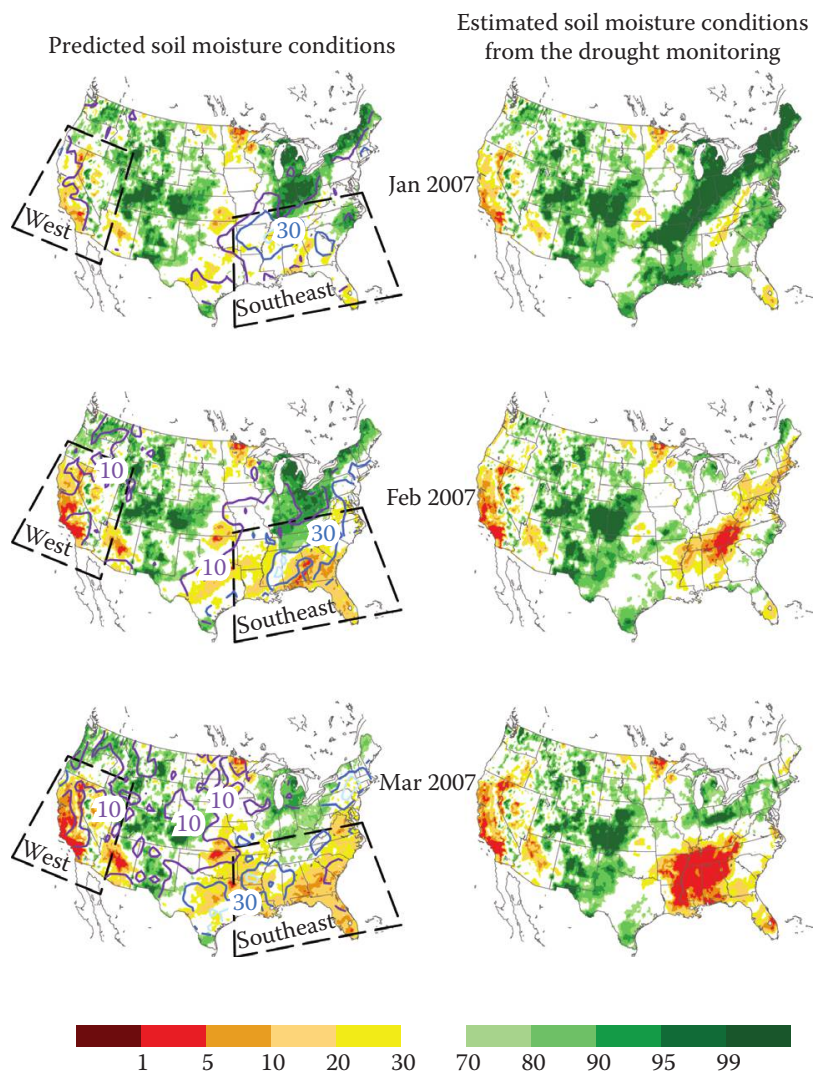

FIGURE 10.8 Example of seasonal prediction of the 2007 U.S. drought (figure reproduced from Luo L. and E.F. Wood, Geophys. Res. Lett., 34, L22702, 2007). Predictions of soil moisture percentiles (\%) (left column) were made starting on January 1, 2007, using downscaled and bias-corrected CFS seasonal climate forecasts to drive the VIC model, and are compared to estimated soil moisture from the real-time drought monitoring (right column). Left column shows the mean of the most likely ensemble set (shaded) and their spread (contour). The boxes indicate regions where drought was most severe during early 2007.

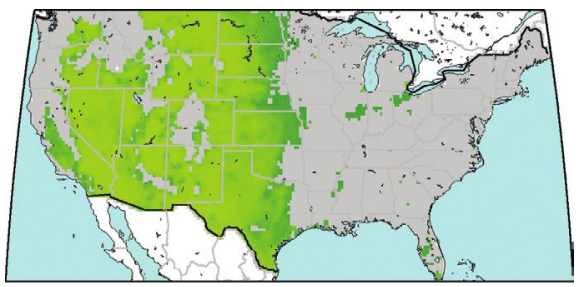

Vegetation water content $\left(\mathrm{kg} \mathrm{m}^{-2}\right)$

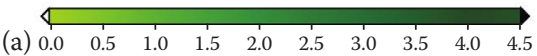

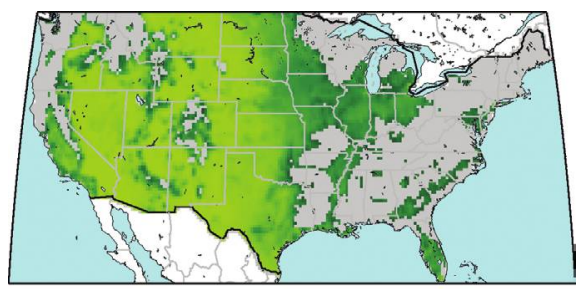

Vegetation water content $\left(\mathrm{kg} \mathrm{m}^{-2}\right)$

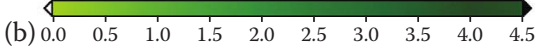

FIGURE 10.9 Zones of applicability for microwave remote sensing retrievals of soil moisture based on penetration through vegetation for frequencies in (a) X-band $(10.7 \mathrm{GHz})$ and (b) L-band $(1.4 \mathrm{GHz})$. Vegetation is characterized by its vegetation water content $\left(\mathrm{kg} \mathrm{m}^{-2}\right)$. Gray shading indicates areas where retrievals of soil moisture are not feasible. 


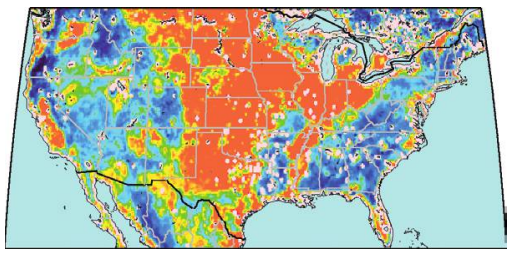

$\%$ Volumetric

(a) 05101520253035404550556065

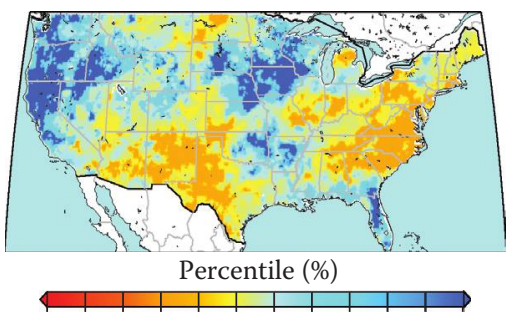

(c) $0 \quad 2 \quad 5 \quad 1020307080909598100$

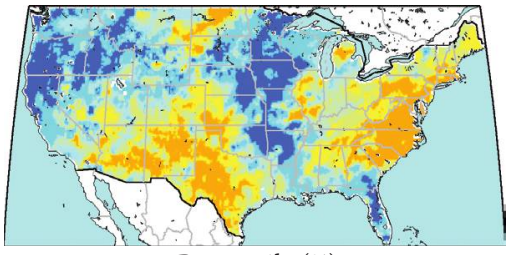

Percentile (\%)

(e) $0 \quad 2 \quad 5 \quad 1020307080909598100$

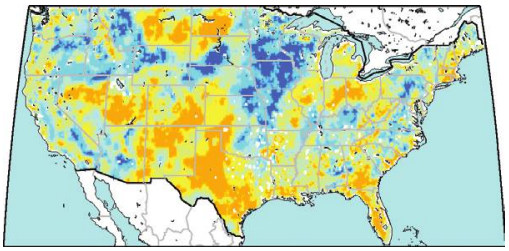

Percentile (\%)

(b) $0 \quad 2 \quad 51020307080909598100$

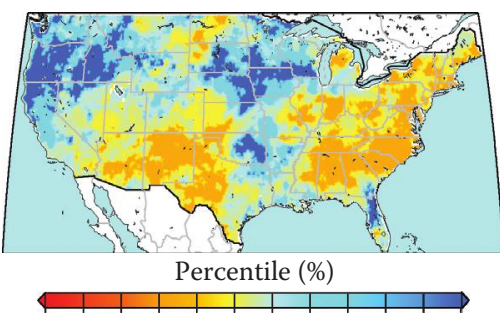

(d) $0 \quad 2 \quad 5 \quad 1020307080909598100$

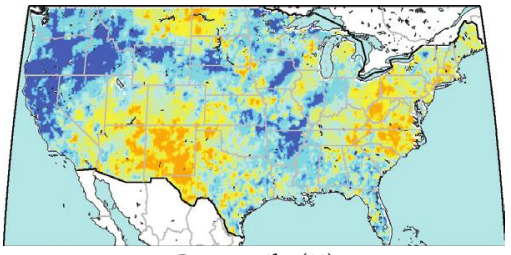

Percentile (\%)

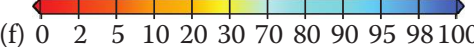

FIGURE 10.10 (a) Dynamic range (\% vol.) of AMSR-E daily soil moisture and (b-f) examples of monthly soil moisture percentiles for October 2007 for (b) AMSR-E, (c) Noah, (d) Mosaic, (e) SAC, and (f) VIC.

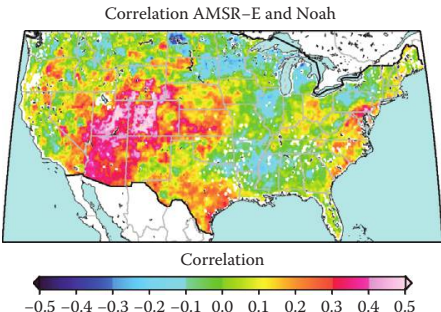

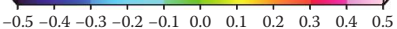

Correlation AMSR-E and SAC

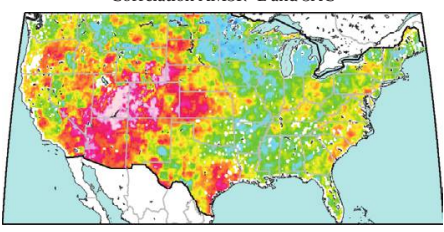

Correlation

$\begin{array}{lllllllll}0 & -0.4 & -0.3 & -0.2 & -0.1 & 0.0 & 0.1 & 0.2 & 0.3\end{array}$

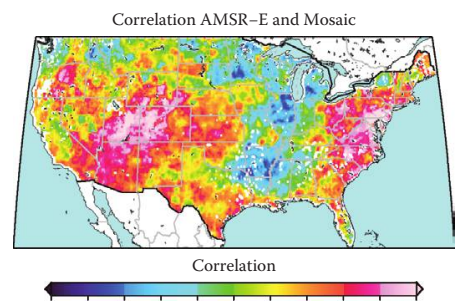

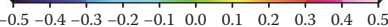

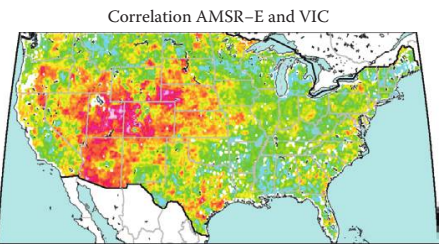

Correlation

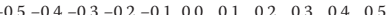

FIGURE 10.12 Correlation between monthly AMSR-E and LSM monthly soil moisture percentiles for 2002-2008. 